\title{
A Clinical Multi-center Study of Pregnant Women with COVID-19 in Hubei, China
}

\section{Shujie Liao ( $\nabla$ sjliao@tjh.tjmu.edu.cn )}

Huazhong University of Science and Technology

\section{R. Wang}

Huazhong University of Science and Technology

D. Wu

Huazhong University of Science and Technology

\section{Fang}

Peking University

\section{Dong}

Huazhong University of Science and Technology

Z. Tao

Egang Hospital of Ezhou City

H. Yang

Huazhong University of Science and Technology

W. Zeng

Huazhong University of Science and Technology

Q. Peng

Egang Hospital of Ezhou City

J. Peng

Huazhong University of Science and Technology

Y. Wu

Wuhan Jiangxia District People's Hospital

S. Chen

Huazhong University of Science and Technology

$X$. Lin

Taihe Hospital Affiliated to Hubei University of Medicine

G. Xiong

The Central Hospital of Wuhan

X. Ma

The Central Hospital of Wuhan

A. You

Maternal and Child Hospital of Huangshi City

L. Lu

The first people's Hospital of Xiaochang County

W. Dai

Wuhan University

C. $\mathrm{Hu}$

Wuhan University

J. Zheng

The First People's Hospital of Xianning

\section{F. Xiao}

Suizhou Central Hospital

\section{Y. Wang}

The people's hospital of Xishui

W. He 
China Three Gorges University

H. Li

China Three Gorges University

H. Xing

Xiangyang Central Hospital Affiliated to Hubei University of Arts and Science

Y. Huang

Xiangyang Central Hospital Affiliated to Hubei University of Arts and Science

D. Sun

Jing Men NO.2 People's Hospital

P. Cheng

The People's Hospital of Fangxian

H. Jin

People's Hospital of Macheng

Z. Zhang

Wuhan Xinzhou District People's Hospital

D. Su

Wuhan Xinzhou District People's Hospital

R. Huang

Wuhan Xinzhou District People's Hospital

C. Zhang

Taihe Hospital Affiliated to Hubei University of Medicine

X. Liu

Taihe Hospital Affiliated to Hubei University of Medicine

\section{Z. Zhang}

Dabieshan Regional Medical Center

Y. Bi

Wuhan Red Cross Hospital

L. Wang

People's Hospital of Huangmei County

X. $\mathrm{Hu}$

The People's Hospital of Hanchuan

Q. Shen

The First People's Hospital of Zaoyang

L. Zhao

The People's Hospital of Hongan

C. Fu

The People's Hospital of Dawu

S. Dai

Wuhan Dongxihu District People's Hospital

R. Du

Wuhan Dongxihu District People's Hospital

L. Wang

The People's Hospital of Jiangling

J. Wu

Huazhong University of Science and Technology

\section{S. Wang}

Huazhong University of Science and Technology

D. Lv

Huazhong University of Science and Technology

R. Long

Huazhong University of Science and Technology

J. Peng

Huazhong University of Science and Technology 


\section{Qian}

Yangxin maternal and Child Health Hospital

\section{Wei Pan}

Renmin University of China

\section{Y. Zhao}

Huazhong University of Science and Technology

\section{Feng}

Huazhong University of Science and Technology

\section{Deng}

Huazhong University of Science and Technology

\section{W. Zhang}

Zhongnan Hospital of Wuhan University

\section{Research Article}

Keywords: COVID-19, multi-center, pregnant, newborn, perinatal period

Posted Date: May 9th, 2020

DOI: https://doi.org/10.21203/rs.3.rs-27398/v1

License: (c) (i) This work is licensed under a Creative Commons Attribution 4.0 International License. Read Full License 


\section{Abstract}

Background: Coronavirus disease 2019 (COVID-19) has rapidly spread to more than 200 countries. Thus far, reports regarding multi-center data from throughout gestation in women with COVID-19 and newborn outcomes are scarce.

Methods: We retrospectively reviewed data from 92 pregnant women with COVID-19 (PW-COVID-19) and their 78 newborns from 27 hospitals in 12 regions of Hubei, China. The demographic, epidemiological, clinical, laboratory, and therapeutic data and pregnancy, perinatal, and neonatal outcomes were analyzed. Follow-up was censored until April 7, 2020.

Findings: Median maternal age was 31.0 years (IQR 28.0-33.0), with nine patients in the first trimester, five in the second trimester, and 78 in the third trimester. None of the patients died, and most $(92.4 \%)$ recovered and were discharged. Seventy-five deliveries (including three sets of twins) comprised 66 cesarean sections and nine vaginal deliveries, with 21 preterm and 57 full-term infants. Seventeen live births had radiological findings of pulmonary infection. One newborn tested positive for SARS-CoV-2 nucleic acid, and three newborns were viral antibody-positive: two $\lg G(+)$ and $\lg M(-)$, and one $\lg G(+)$ and $\lg M(+)$. The median suspected duration of virus exposure was 7 days (IQR 0 to 27).

Interpretation: Compared to the pregnant women with other viral infections, such as SARS, MERS, and Zika virus infection, PW-COVID-19 had similar manifestations and relatively better outcomes. The termination time and delivery mode in PW-COVID-19 should be evaluated based on both the maternal and fetal situations. The possibility of maternal-to-fetal transmission of SARS-CoV-2 requires further investigation.

Authors Shujie Liao and Renjie Wang contributed equally to this work.

\section{Key Points}

Question: What is the distinctive clinical course, pregnancy, and neonatal outcomes of the pregnant women with COVID-19?

Findings: This is the first comprehensive retrospective multi-center study in pregnant women with COVID-19.We retrospectively reviewed the demographic, epidemiological, clinical, laboratory, and therapeutic data and pregnant, perinatal, and neonatal outcomes of 92 pregnancy cases with COVID-19 and a follow-up of 78 neonates born to these mothers from 27 hospitals in 12 regions of Hubei province, China.

Meaning: Compared to the pregnant women with other viral infections, such as SARS, MERS, and Zika virus infection, PW-COVID-19 had similar manifestations and relatively better outcomes.

\section{Introduction}

In December 2019, the novel coronavirus disease 2019 (COVID-19) of unknown origin was identified in Wuhan, the capital city of Hubei province, China. ${ }^{1}$ As of April 30, 2020, a total of 3,090,445 patients with COVID-19 had been confirmed and 217,769 deaths reported worldwide, ${ }^{2}$ and the World Health Organization (WHO) had declared COVID-19 a pandemic. ${ }^{3}$ The virus, officially named severe acute respiratory syndrome coronavirus 2 (SARS-CoV-2), belonged to the same $\beta$-coronavirus genus as severe acute respiratory syndrome coronavirus (SARS-CoV) and Middle East respiratory syndrome coronavirus (MERS-CoV), which were reported to have high morbidity and mortality, particularly adverse pregnancy outcomes in pregnant women. ${ }^{4,5}$

According to a nationwide epidemiological survey in China on February 18, 2020, at least 252 pregnant women were suspected of having COVID-19, including 115 confirmed cases, 75 (65.2\%) of which occurred in Hubei province. ${ }^{6}$ Till April 2, 2020, one of epidemiological survey had showed no more than 150 cases of COVID-19 in pregnant women around China. ${ }^{7}$ To date, several reports have been published regarding patients with COVID-19, but reports focusing on pregnant women remain scarce and have been limited by small sample sizes, the nature of single-center studies, few data on clinical course, pregnancy, and neonatal outcomes, and lack of information on characteristics throughout gestation, especially those in the first and second trimester. 8,9

Whether pregnant women with COVID-19 (PW-COVID-19) have a different clinical course and adverse outcomes compared to non-pregnant patients and other virus infection diseases such as SARS, MERS, Zika, etc., or whether suffering from COVID-19 was necessary for the immediate termination of pregnancy or cesarean delivery, or whether the suspected duration of virus exposure could induce an adverse impact on the fetus remain unknown. To address these problems, we performed the first comprehensive retrospective multi-center study on the whole gestation period in PW-COVID-19 in Hubei province, China.

\section{Research in context}


We searched PubMed and China National Knowledge Infrastructure database on April 7, 2020, for articles that described the features of patients in pregnancy infected with severe acute respiratory syndrome coronavirus 2 (SARS-CoV-2), using the search terms ("novel coronavirus" OR "COVID-19" OR "SARS-CoV-2") AND ("pregnancy" OR "maternal outcome" OR "fetal infection") with no language or time restrictions. We found several articles and case reports on pregnant women with COVID-19. However, no published works were found about the multi-center data analysis based on the whole gestation period with COVID-19 and considering the outcomes among pregnancy women, fetus and newborns.

\section{Added value of this study}

We retrospectively reviewed the demographic, epidemiological, clinical, laboratory, and therapeutic data and pregnant, perinatal, and neonatal outcomes of 92 pregnancy cases with COVID-19 throughout the gestation period and a follow-up of 78 neonates born to these mothers from 27 hospitals in 12 regions of Hubei province, China. None of the patients died, and most (92.4\%) recovered and were discharged. Seventy-five deliveries (including three sets of twins) comprised 66 cesarean sections and nine vaginal deliveries, with 21 preterm and 57 full-term infants. Seventeen live births had radiological findings of pulmonary infection. One newborn tested positive for SARS-CoV-2 nucleic acid, and three newborns were viral antibody-positive: two $\lg G(+)$ and $\lg M(-)$, and one $\lg G(+)$ and $\lg M(+)$.

\section{Implications of all the available evidence}

Compared to the pregnant women with other viral infections, such as SARS, MERS, and Zika virus infection, pregnant women with COVID-19 had similar manifestations and relatively better outcomes. The most appropriate time and delivery mode for the termination of pregnancy should be evaluated based on both the maternal and fetal situations. The possibility of maternal-to-fetal transmission of SARS-CoV-2 requires further investigation.

\section{Methods}

\section{Study design and participants}

This retrospective study included 92 hospitalized PW-COVID-19 from 27 hospitals in Hubei province, China, between January 15 and April 7 , 2020. The case sources were listed in the appendix (Table S1). Follow-up was censored until April 7, 2020. COVID-19 was diagnosed based on the New Coronavirus Pneumonia Prevention and Control Program (5th-7th trial edition) published by the National Health Commission of China. ${ }^{10,11}$ Patients with laboratory-confirmed infection were defined as positive tests by high-throughput sequencing or real-time reversetranscriptase polymerase chain reaction (RT-PCR) or serum-specific IgG and IgM antibody against SARS-Cov-2. Clinically diagnosed infection was defined as suspected cases with imaging features of pneumonia. Medical Ethical Committee approval from Tongji Hospital, Tongji Medical College of Huazhong University of Science and Technology was obtained. Data were analyzed and interpreted by the authors. All the authors reviewed the manuscript and vouch for the accuracy and completeness of the data and the adherence of the study to the protocol.

\section{Data collection}

Medical records, including demographics, epidemiology, clinical, laboratory, and imaging examination, treatment measures, and maternal and fetus outcomes, were obtained from electronic health records. Patients who had been discharged from the hospital and newborns were followed up by Di Wu, Rui Long, Dan Lv, and Jing Peng. Data were summarized in a computerized data collection form and follow-up censored untill April 7, 2020. Researchers Shujie Liao, Renjie Wang, Wanqiang Dai, Cheng Hu, and Wei Pan independently reviewed and analyzed the data. Any discrepancy was solved by a senior clinician, Yun Zhao, Ling Feng, Dongrui Deng, and Wei Zhang. The missing information was sent to the coordinators, who subsequently contacted the clinicians at each center.

\section{Laboratory procedures}

Laboratory confirmation of SARS-Cov-2 based on RT-PCR assays was described previously. ${ }^{1,10}$ Briefly, nasopharyngeal swab specimens were collected from all patients after the onset of symptoms or on admission and were tested using kits from Shanghai Pfizer Pharmaceuticals., Ltd. The testing was repeated twice every 24 hours. Before January 23, 2020, the laboratory confirmation was conducted at the Chinese Center for Disease Prevention and Control, and subsequently in certified tertiary care hospitals. The test for SARS-CoV-2 antibody IgG and IgM used kits from YHLO (YHLO Biotech Co., Ltd. Shenzhen, China). ${ }^{12}$

Laboratory assessments, including a complete blood count, blood biochemistry, C-reactive protein, procalcitonin, liver and renal function, lactate dehydrogenase, creatine kinase, and coagulation test, were conducted according to the clinical care routine upon admission.

Computed tomography (CT) was performed for inpatients at admission with the patient's consent. The criteria for discharge were an absence 
of fever for at least three days, remission of respiratory symptoms, substantial improvement in the lungs on imaging, and two consecutive negative nucleic acid tests (NATs) at least 24 hours apart. ${ }^{10}$

\section{Definitions}

The severity of COVID-19 was defined as mild (mild clinical symptoms and no pneumonia on imaging), moderate (presence of fever, respiratory symptoms, and pneumonia on imaging), severe (respiratory distress, respiratory rate $\geq 30$ times/min, oxygen saturation $\leq 93 \%$ at rest, or partial arterial oxygen pressure $\left[\mathrm{PaO}_{2}\right] /$ oxygen absorption concentration $\left[\mathrm{FiO}_{2}\right] \leq 300 \mathrm{mmHg}[1 \mathrm{mmHg}=0 \cdot 133 \mathrm{kPa}]$ ), or critical (respiratory failure requiring mechanical ventilation, or shock or failure of other organs requiring ICU treatment). ${ }^{10}$ The composite endpoint

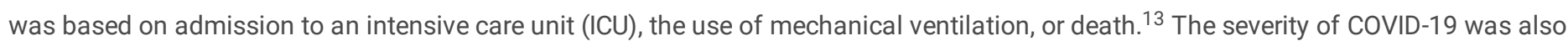
categorized as severe or non-severe based on the American Thoracic Society (ATS) guidelines for community-acquired pneumonia. ${ }^{14}$ The linkage to Wuhan was defined as living in Wuhan, visiting Wuhan recently, or having contact with Wuhan residents. The incubation period was defined as the interval between the potential earliest exposure to the transmission source (wildlife, or suspicious or confirmed patients) and the earliest onset of symptoms. Incubation periods $<1$ day were excluded because of the continuous exposure. The suspected duration of virus exposure was defined as the interval between the potential earliest exposure to the transmission source, or the earliest onset of symptoms or the date of disease confirmation, and the date of delivery or the last date of follow-up. Family cluster of COVID-19 was defined as two or more cases with confirmed COVID-19 reported within a given family in two weeks. Fever was defined as an axillary temperature of $37.5^{\circ} \mathrm{C}$ or higher. Puerperium is defined as the 6-week period following childbirth during which the woman's body almost returns to its prepregnancy state. ${ }^{15}$ Fetal heart monitoring was performed weekly for pregnancies after 28 weeks. Fetal growth was assessed by serial ultrasound scans every two weeks. The gestation period was calculated from the first day of the last menstrual period and was approximately 280 days (40 weeks), clinically divided into three periods: < 14 weeks is the first trimester, 14 weeks to $27+6$ weeks is the second trimester, and $\geq 28$ weeks is the third trimester. ${ }^{16}$

\section{Statistical analysis}

Statistical analysis was done with R 3.6.2 (2019-12-12) and Excel 2016, and p values of $<0 \cdot 01,<0 \cdot 05$ and $<0 \cdot 10$ were considered as the presence of statistical significance. Continuous variables were directly expressed as medians and interquartile ranges or ranges. Categorical variables were expressed as number and percentages. Chi-square test and single-ratio z-test separately were used for comparison of categorical variables, while single population t-test was used for continuous variables. The ArcGIS, version $10 \cdot 2 \cdot 2$ was used to plot the numbers of confirmed patients in each region on the map.

\section{Role of the funding source}

The funder of the study did not participate in study design, data collection, data analysis, data interpretation, or writing of the report. The corresponding authors had full access to all the data in the study and had final responsibility for the decision to submit for publication.

\section{Results}

\section{Clinical characteristics, laboratory results, treatments, and outcomes}

Of the 92 PW-COVID-19 included in the study, $47(51 \cdot 1 \%)$ were residents of Wuhan. Other patients $(n=45)$ were distributed in 11 regions outside Wuhan, which accounted for 12/17 of the regions in Hubei province (Figure 1, Table S1). The demographic, epidemiological, and clinical characteristics, radiological findings, treatments, and outcomes are given in Table 1. The median patient age was 31.0 years (IQR 28.0 to 33.0). Nine pregnant women were in the first trimester, five in the second trimester, and 78 in the third trimester. The information of COVID19 of all their family members was followed up until April 7, 2020. Fifteen patients (18.1\% of 83 cases) had family clusters, and 77 patients (85.6\% of 90 cases) had a link to Wuhan. The median incubation period was 8.0 days (IQR 6.75 to 14.25), which was longer than in patients with COVID-19 in the general population (GP-COVID-19). ${ }^{13} 22$ patients ( $25 \cdot 3 \%$ of 87 cases) had at least one comorbidity (e.g., hypertension, diabetes mellitus, hypothyroidism).

Fever was observed in 37.9\% (33 of 87 cases) at admission, but only 25.7\% (19 of 74 cases) had fever during hospitalization. The most common symptoms were similar to GP-COVID-19 in the literature, ${ }^{13}$ but the incidence of fever $(25 \cdot 7 \%$ vs. $88 \cdot 7 \%, P<0 \cdot 0001)$, cough (42.5\% vs. $67 \cdot 8 \%, P<0 \cdot 0001)$, fatigue (14.9\% vs. $38 \cdot 1 \%, P<0 \cdot 0001)$, and myalgia (2.3\% vs. $14.9 \%, P=0 \cdot 0019)$ was lower.

Among 91 cases (one pregnant woman refused the imaging examination), $89.0 \%$ had abnormalities on chest CT. Ground-glass opacity was found in $44.0 \%$ of cases and local patchy shadowing in $59 \cdot 3 \%$ of cases, whereas interstitial abnormalities presented in only one case. 
The laboratory results for PW-COVID-19 are shown in Table S2. Laboratory findings, such as leukopenia; lymphopenia; decreased levels of eosinophils, total protein, and albumin; and elevated levels of neutrophils, C-reactive protein, procalcitonin, aminotransferase, lactate dehydrogenase, fibrinogen, D-dimer, and fibrin degradation products, were observed in both PW-COVID-19 and GP-COVID-19. However, compared to GP-COVID-19, PW-COVID-19 seemed to less frequently have elevated C-reactive protein (75.0\% vs. 91.9\%, P=0.0042) and D-dimer $(20 \cdot 8 \%$ vs. $46 \cdot 4 \%, P=0 \cdot 012)$, but more frequently had elevated procalcitonin $(21 \cdot 9 \%$ vs. $5 \cdot 5 \%, P=0 \cdot 0025)$.

Most patients were categorized as moderate cases ( $82 \cdot 6 \%$ of 92 cases), but five patients (5.4\%) and one patient (1.1\%) were severe and critical cases, respectively. The distribution of COVID-19 severity in different age groups and gestation periods is shown in Figure S1 and Figure S2. Based on the ATS guidelines, only two patients were classified as severe, which was significantly lower than GP-COVID-19 (2.2\% vs. $15 \cdot 7 \%, P<0 \cdot 0001) .{ }^{13}$

As for the treatment and clinical outcomes, PW-COVID-19 were more likely to receive oxygen therapy $(59 \cdot 0 \%$ vs. $41 \cdot 3 \%, \mathrm{P}=0 \cdot 0034)$ and antibiotic therapy $(93.6 \%$ vs. $58.0 \%, \mathrm{P}<0.0001)$, whereas antiviral therapy (including interferon alpha, lopinavir/ritonavir, ribavirin, or arbidol) (19.5\% vs. $35 \cdot 8 \%, P<0.0001)$, systemic glucocorticoids ( $6.4 \%$ vs. $18 \cdot 6 \%, P=0.010)$, and intravenous immune globulin ( $3.8 \%$ vs. $13 \cdot 1 \%, P=0.027)$ were used less often than in GP-COVID-19. ${ }^{13}$ Mechanical ventilation was used in two patients. The median hospital stay was $9 \cdot 5$ days (IQR $5 \cdot 25$ to $15 \cdot 00)$, which was a little shorter than reported for GP-COVID-19. ${ }^{13}$

No patient died, and most of the patients ( $92 \cdot 4 \%$ of 92 cases) recovered and were discharged from the hospital by the end of follow-up. The composite endpoint occurred in 17/78 patients (21.8\%); 17 patients were admitted to the ICU, and two required mechanical ventilation. These patients had a similar clinical course compared to those without a composite endpoint. Regarding the two patients requiring mechanical ventilation, one was in the first trimester and ended up having an induced abortion, the other was in the third trimester and underwent full-term delivery by cesarean section (CS). Both cases had mild symptoms at admission and no complications at delivery. Two patients recovered well, and one has discharged from the hospital by the date of data collection.

\section{Characteristics of PW-COVID-19 compared to SARS, MERS, Zika virus infection, and H1N1 infection in pregnant women}

The maternal age and affected family members were similar among PW-COVID-19 and pregnant women infected with SARS and MERS. Fever and cough were the most common symptoms among PW-COVID-19 and pregnant women infected with SARS, MERS, and H1N1. The presence of these two symptoms was lowest among PW-COVID-19 (42.5\% vs. $100 \%, 81 \cdot 8 \%$, and $97 \cdot 0 \%$; $42 \cdot 5 \%$ vs. $75 \%$, 63.6\%, and 84\%, respectively). Other symptoms, such as diarrhea, myalgia, and dyspnea were less common in PW-COVID-19. Regarding treatment, compared to SARS and MERS, PW-COVID-19 received less systemic glucocorticoids (6.4\% vs. $91 \cdot 7 \%$ compared to SARS, P<0.0001), mechanical ventilation ( $2 \cdot 6 \%$ vs. $33 \%$ compared to SARS, $\mathrm{P}=0.00079 ; 2 \cdot 6 \%$ vs. $45 \cdot 5 \%$ compared to MERS, $\mathrm{P}<0.0001)$, and intensive care ( $21 \cdot 8 \%$ vs. $50 \cdot 0 \%$ compared to SARS, $\mathrm{P}=0.084 ; 21 \cdot 8 \%$ vs. $63.6 \%$ compared to MERS, $\mathrm{P}=0.010)$. Compared to H1N1 infection, PW-COVID-19 had a similar proportion of admission to the ICU and less often used mechanical ventilation ( $2 \cdot 6 \% \mathrm{vs} .18 \cdot 8 \%$, $\mathrm{P}=0 \cdot 00067)$. The mortality rate of infected pregnant women was $25 \%$ in SARS ( $n=3), 27 \cdot 3 \%$ in MERS ( $n=3), 2 \cdot 3 \%$ in Zika virus, and $4.3 \%$ in H1N1, but no death was noted in our PWCOVID-19 data. Due to the limited investigations of the adverse maternal and neonatal complications of COVID-19 and the consideration of vertical transmission risk of SARS-CoV-2 in the early period of epidemic, some full-term pregnant women with COVID-19 underwent emergency CS after admission. 8,9,17 PW-COVID-19 had a much higher proportion of CS than SARS (71·7\% vs. 33.3\%, P=0.019), MERS (71·7\% vs. $36 \cdot 4 \%, \mathrm{P}=0.042)$, and $\mathrm{H} 1 \mathrm{~N} 1$ (71.7\% vs. $18.6 \%, \mathrm{P}<0.0001$; Table 2$)$. The basic epidemiological characteristics of viral infection among COVID-19, SARS, MERS, Zika, and H1N1 in the general population are provided in Table S3.

\section{Pregnancy outcomes of suspected duration of virus exposure on PW-COVID-19}

The median suspected duration of virus exposure for PW-COVID-19 was 7 days (IQR 0 to 27). Decreased gestational weight gain was noted in $7 / 58$ cases $(12 \cdot 1 \%)$. The blood pressure, fundal height, abdominal circumference, and fetal heart rate in each group were within the reference range. ${ }^{16}$ The overall rate of complications in all patients was less common than in the literature. ${ }^{16,18-20}$ Seven of the nine patients (77.8\%) who presented in the first trimester had induced abortions without any pathological indications for pregnancy termination; all were based on the patients' requests and after being informed of the risk and signing informed consent. One case in the second trimester was stillborn; the fetus was in fetal distress and exhibited fetal growth restriction before the potential earliest exposure to the transmission source, and there was no direct relationship between the fetal death and COVID-19. Twenty-one patients in the third trimester (26.9\%) underwent preterm delivery. By April 7, 2020, data has been collected on 22 patients who received antenatal care. Data on antenatal care from 13 fetus and neonates born to PW-COVID-19 after virus exposure are shown in Table S4.

\section{Perinatal and neonatal outcomes}


A total of 78 newborns born to PW-COVID-19 were recorded and followed up, including three sets of twins. Forty (51.3\%) newborns were male. Twenty-one newborns (26.9\%) were preterm infants, and nine newborns (11.5\%) were delivered vaginally. The mean 1-min Apgar score of 66 newborns was $8 \cdot 76 \pm 0 \cdot 91$, and the 5 -min Apgar score was $9 \cdot 50 \pm 0.93$. Of 61 newborns with available data, $88.52 \%$ received artificial feeding and $9 \cdot 84 \%$ were mixed mode, including breast and artificial feeding (Table 4 ).

Premature rupture of membrane (PROM) occurred in seven singletons and one twin. Of 78 newborns, 13 pregnancies (16.67\%) had cord entanglement, ten cases (12.82\%) had meconium-stained amniotic fluid, and three cases (3.85\%) had an atrial septal defect (ASD). The mobility of the above four diseases was much higher than that of the reference range. ${ }^{21,22}$ Fetal distress was observed in 18 newborns (23.08\% of 78 cases). Twenty of 62 cases $(31 \cdot 67 \%)$ had hyperbilirubinemia (Table 4$)$.

The median gestational age at delivery in preterm infants, full-term infants, vaginal delivery, and CS was $36+1$ weeks, $38+4$ weeks, 38 weeks, and 39+6 weeks, respectively. As shown in Table 4, we found no significant difference in regards to abnormal fetus and appendages, neonatal disease, the morbidity of COVID-19, or imaging findings between term and preterm infants, or between vaginal delivery and CS infants.

SARS-CoV-2 NAT was positive in one newborn (\#69). The viral antibody test was positive in three newborns: two (\#36 and 57) with IgG (+) and IgM (-), and one (\#68) with IgG (+) and IgM (+). For newborn \#69, 36 hours after emergency CS at 40 weeks, the SARS-CoV-2 NAT was positive. The infant eventually recovered and was discharged 16 days after delivery. Patient \#36 underwent a full-term vaginal delivery, and patient \#57 delivered by CS at 38+1 weeks. The SARS-CoV-2 NATs were negative, but both had signs of pneumonia on imaging. For newborn \#68, 19 hours after CS at 38 weeks, viral antibody tests were $\operatorname{lgG}(+)$ and $\operatorname{lgM}(+)$. The newborn met the criteria for discharge and was discharged from the hospital on March 20. Pulmonary infections were observed on imaging in 17/34 cases (50.0\%). We had two assisted reproductive technology (ART) PW-COVID-19 cases. Their maternal and fetal outcomes were not significantly different from spontaneous pregnancy (Table 4).

\section{Discussion}

In the current study, we collected and analyzed the clinical data and outcomes from 92 PW-COVID-19 and 78 neonates born to these mothers, which is the first comprehensive multi-center study regarding maternal, fetal, and neonatal outcomes throughout gestation.

Pregnancy is considered to have greater susceptibility to certain infections because of great changes in the respiratory system due to hormonal and physiological variations and the special immunosuppressive state. However, tolerance to the semi-allogeneic fetus does not mean an overall systemic immune response; in contrast, the tolerance in the uterus is transient hypo-responsiveness, and the systemic immune system appears to be well-modulated during pregnancy. ${ }^{23,24}$ Previous studies have demonstrated poor outcomes in pregnant women infected with SARS, MERS, and H1N1.4,25,26 Binding with similar affinities to angiotensin-converting enzyme 2 (ACE2) and having 85\% sequence similarity with SARS, patients infected with SARS-CoV-2 are considered to have similar adverse outcomes. ${ }^{27}$ However, in our studies, PW-COVID-19 appear to have similar clinical characteristics, ${ }^{1,13}$ milder severities, better clinical course, and better outcomes with a 0\% mortality rate, and PW-COVID-19 also have a lower proportion of maternal death, pregnancy loss, and fetal death than SARS and MERS. Based on our studies, there is little evidence to indicate that PW-COVID-19 has more adverse outcomes. Some research has hinted that SARSCoV-2 has similar affinities as SARS-CoV for binding the same receptor, ACE2, but mutation of the protein induced a higher incidence of infection and lower pathogenicity. ${ }^{1,27}$ The different outcomes of various virus-related diseases in pregnant women require more research of their pathogenesis to find potential targeted prophylactic and therapeutic strategies.

Sixty-six pregnant women (88.0\% of 75 cases) underwent CS and nine underwent a vaginal delivery. In addition, we found no significant difference in the maternal, perinatal, and neonatal outcomes between vaginal delivery and CS (Figure S3). Therefore, vaginal delivery could be considered for patients with a mild infection, stable condition, normal birth canal and satisfied labor stage, no perinatal complications, and negative NAT in vaginal discharge. 6,17

The median suspected duration of virus exposure was 7 days. The relationship between suspected duration of virus exposure and pregnancy outcomes is provided in Table 3, Table 4, Table S5, and Figure S4. In addition, our data seem to indicate that the occurrence of fetal distress, meconium-stained amniotic fluid, and PROM correlates with the duration of exposure. However, whether the duration of virus exposure had an impact on the adverse outcomes of pregnancy requires more investigations.

Until now, no direct evidence has been available on maternal-to-fetal transmission of SARS-CoV-2 in pregnancy. ${ }^{8,9}$ Some research has shown that the predominant receptor of sensitive cells for SARS-CoV-2 is expressed at very low levels in the human maternal-fetal interface. ${ }^{27,28}$ In our research, a very important finding is the possible infection of newborns (Table 4). One newborn (\#69) had a positive for SARS-CoV-2 NAT, and three newborns (\#36, 57, and 68) were positive for viral antibody. After the first positive SARS-CoV-2 NAT, newborn \#69 tested negative in subsequent NATs of nasopharyngeal and anal swabs, recovered well, and was discharged from the hospital 16 days after delivery. The 
newborns' antibody test was still negative 46 days after delivery, whereas the mother was IgG (+) and IgM (-). The CT scan of the mother on April 1 showed further absorption compared to that on February 24. Considering the lack of NATs of intrauterine tissue samples and series of negative tests, intrauterine transmission remained unconfirmed. Newborns \#36 and 57 both had signs of pneumonia on imaging but were negative on the SARS-CoV-2 NAT. Mother \#68 had a positive NAT at 33+6 weeks, which was negative in the subsequent three repeats. Newborn \#68 was viral antibody $\operatorname{lgG}(+)$ and $\operatorname{lgM}(+)$ in the cord blood and neonatal peripheral blood within the first day after CS at 38 weeks. Nasopharyngeal swabs, anal swabs, urine, peripheral blood, gastric juice before feeding, and intrauterine tissue samples, including amniotic fluid, cord blood, and placenta were collected and SARS-CoV-2 NATs were all negative. However, the viral antibody tests remained positive in the subsequent five repeats in neonatal peripheral blood. A possible reason for this finding may be that IgG is transmitted vertically from the mother through the fetal blood supply, and the fetus may acquire defense against the virus to some extent. The lgM in cord blood and peripheral blood within the first day after delivery indicates the possibility of vertical transmission. However, we need more direct evidence. The mother \#68 had a history of chronic hepatitis B virus (HBV) infection with a hepatitis B surface antigen (HBsAg) level > 250 IU/ml. Previous studies regarding HBV infection and vertical transmission have found that high levels of HBsAg and HBV DNA in the circulation may impact maternal immunity, and the incidence of fibrinoid necrosis and chorionic hyperemia in the placenta is much higher in fetal infection than controls ( $29 \%$ vs. $9 \%$, and $50 \%$ vs. $15 \%) .{ }^{29,30}$ Microdamage to the placental barrier by HBV infection and frequent uterine contraction after 36 weeks may play a role in possible COVID-19 vertical transmission ${ }^{30}$. Thus, the treatment and assessment of PW-COVID-19 with other complications must be personalized. More studies are required to fully illustrate the incidence, risk factors, and possible prophylactic measures for intrauterine transmission of SARS-CoV-2.

Our study has some limitations. First, this study was retrospective and, given the variation in different electronic databases at multiple centers, some laboratory tests were incomplete. Second, lack of appropriate control groups which were matched for age, gender, and comorbidities, so it was hard to conclude the authentic different characteristics between PW-COVID-19 and GP-COVID-19. Third, because the times of the SARS-CoV-2 NATs varied among patients, and obvious symptoms or clear exposure history were lacking in some patients, the calculation of suspected duration of virus exposure may not be entirely accurate. Fourth, the limited number of patients in some subgroups (e.g., patients in the first and second trimester, patients delivered vaginally) require more relevant cases research.

In conclusion, our study showed that PW-COVID-19 have similar manifestations but relatively mild severity compared to other viral infections during pregnancy. Suffering from COVID-19 may not be an absolute indication for immediate termination of pregnancy and cesarean delivery. The most appropriate time and delivery mode for the termination of pregnancy should be determined by a comprehensive assessment of both maternal and fetal conditions. The possible presence of maternal-to-fetal transmission of SARS-CoV-2 requires further investigation. The relationship between COVID-19 and ART requires more in-depth research. Family cluster of PW-COVID-19 (see Table 1) should also be considered. Close contact tracing and family cluster surveillance are recommended for better protection of pregnant women. These data will help support clinical risk-stratification and personalized treatment strategies.

\section{Declarations}

\section{Contributors}

ShuJie Liao (Department of Obstetrics and Gynecology, Tongji Hospital, Tongji Medical College, Huazhong University of Science and Technology) made substantial contributions to the study concept and design. Ling Feng, Dongrui Deng (Department of Obstetrics and Gynecology, Tongji Hospital, Tongji Medical College, Huazhong University of Science and Technology), Yun Zhao (Department of Obstetrics, Maternal and Child Health Hospital of Hubei Province, Tongji Medical College, Huazhong University of Science and Technology), Wei Zhang (Zhongnan Hospital of Wuhan University) had full access to all of the data in the study and take responsibility for the integrity of the data and the accuracy of the data analysis and was responsible for obtaining written consent from patients and obtaining ethical approval. ShuJie Liao, Wanjang Zeng, Suhua Chen, Xingguang Lin, Jianli Wu, Shaoshuai Wang, Ling Feng, Dongrui Deng (Department of Obstetrics and Gynecology, Tongji Hospital, Tongji Medical College, Huazhong University of Science and Technology), Zhengui Tao, Qionglin Peng (Egang Hospital of Ezhou City), Hui Yang, Jing Peng, Yun Zhao (Department of Obstetrics, Maternal and Child Health Hospital of Hubei Province, Tongji Medical College, Huazhong University of Science and Technology), Dirong Dong, Wei Zhang (Zhongnan Hospital of Wuhan University), Jing Peng , Yuping Wu (Wuhan Jiangxia District People's Hospital), Guoping Xiong, Xiulan Ma (The Central Hospital of Wuhan), Aiping You (Maternal and Child Hospital of Huangshi City), Liping Lu (The First People's Hospital of Xiaochang County), Jun Zheng (The First People's Hospital of Xianning), Fengyi Xiao (Suizhou Central Hospital), Yangchun Wang (The people's hospital of Xishui), Wencong He, Hua Li (Yichang Central People's Hospital, The First College of Clinical Medical Science, China Three Gorges University), Hui Xing, Yanli Huang (Xiangyang Central Hospital Affiliated to Hubei University of Arts and Science), Derong Sun (Jing Men NO.2 People's Hospital), Ping Chen (The People's Hospital of Fangxian), Hongmei Jin (People's Hospital of Macheng City), Zhuchun Zhang, Dongfang Su, Rong Huang (Wuhan Xinzhou District People's Hospital), Chunlian Zhang, Xueqin Liu (Taihe Hospital Affiliated to Hubei University of Medicine), Zhian Zhang (Huanggang Central Hospital, Dabieshan Regional Medical Center), Ying Bi (Wuhan Red Cross Hospital), Ling Wang (People's Hospital of 
Huangmei County), Xiaoling Hu (The People's Hospital of Hanchuan), Qibo Shen (The first people's hospital of Zaoyang), Liucheng Zhao (The People's Hospital of Hongan), Cuimin Fu (The People's Hospital of Dawu), Shulan Dai, Rong Du (Wuhan Dongxihu District People's Hospital), Ling Wang (The People's Hospital of Jiangling), Chao Qian(Yangxin maternal and Child Health Hospital) was responsible for data collection and confirmation. ShuJie Liao, Renjie Wang, Di Wu, Dan Lv, Rui Long (Department of Obstetrics and Gynecology, Tongji Hospital, Tongji Medical College, Huazhong University of Science and Technology), Dong Fang,(Andrology Center, Peking University First Hospital; Department of Urology, Peking University First Hospital; Institute of Urology, Peking University), Wan-qiang Dai, Cheng Hu (School of Economic and Management, Wuhan University), Wei Pan (School of Applied Economics, Renmin University of China) made substantial contributions to data acquisition, analysis, and interpretation. ShuJie Liao, Renjie Wang (Department of Obstetrics and Gynecology, Tongji Hospital, Tongji Medical College, Huazhong University of Science and Technology) drafted the manuscript. All authors agree to be accountable for all aspects of the work in ensuring that questions related to the accuracy or integrity of any part of the work are appropriately investigated and resolved.

\section{Competing interest statement}

All authors have completed the ICMJE uniform disclosure form at www.icmje.org/ coi_disclosure.pdf and declare: support from the National Natural Science Foundation of China, the Chinese Medical Association of Clinical Medicine special funds for scientific research projects and the Chinese Medical Association of Clinical Medicine special funds for scientific research projects for the submitted work; no financial relationships with any organisations that might have an interest in the submitted work in the previous three years, no other relationships or activities that could appear to have influenced the submitted work.

\section{Funding}

This study was supported by the National Clinical Research Center for Obstetrics and Gynecology (2015BAl13B05); the National Natural Science Foundation of China (81672085; 81372804; 81873843); the Chinese Medical Association of Clinical Medicine special funds for scientific research projects (17020400709), and the Hubei Provincial Natural Science Foundation of China (2019CFA062).

\section{Patient and public involvement}

Patients or the public were not involved in the design, data collection, analyses, or interpretation of this research.

\section{References}

1. Huang C, Wang Y, Li X, et al. Clinical features of patients infected with 2019 novel coronavirus in Wuhan, China. The Lancet 2020; 395(10223): 497-506.

2. Organization WH. Coronavirus disease 2019 (COVID-2019): situation report-101. April 30, 2020.https://www.who.int/docs/defaultsource/coronaviruse/situation-reports/20200430-sitrep-101-covid-19.pdf?sfvrsn=2ba4e093_2(accessed May 01, 2020).

3. WHO Director-General's opening remarks at the media briefing on COVID-19 - 11 March 2020. https://www.who.int/dg/speeches/detail/who-director-general-s-opening-remarks-at-the-media-briefing-on-covid-19-11-march-2020 (accessed March 20 2020).

4. Wong SF, Chow KM, Leung TN, et al. Pregnancy and perinatal outcomes of women with severe acute respiratory syndrome. American journal of obstetrics and gynecology 2004; 191(1): 292-7.

5. Musso D, Ko Al, Baud D. Zika Virus Infection - After the Pandemic. The New England journal of medicine 2019; 381 (15): $1444-57$.

6. Qiao J, Zhao Y. National obstetrics medical quality management and control center. Advice on management of "COVID-19" in pregnant women during delivery. Chinese Journal of Obstetrics and Gynecology 2020; 55(3): E007.

7. No more than 150 pregnant women in China have been infected with the new crown, and about $2 \%$ of them are critically ill. April $2,2020$. http://www.bjd.com.cn/a/202004/02/WS5e860466e4b09b10aad5e110.html (accessed April 6, 2020).

8. Chen H, Guo J, Wang C, et al. Clinical characteristics and intrauterine vertical transmission potential of COVID-19 infection in nine pregnant women: a retrospective review of medical records. The Lancet 2020; 395(10226): 809-15.

9. Yu N, Li W, Kang Q, et al. Clinical features and obstetric and neonatal outcomes of pregnant patients with COVID-19 in Wuhan, China: a retrospective, single-centre, descriptive study. The Lancet Infectious Diseases 2020.

10. New coronavirus pneumonia prevention and control program (5th trial edition). (in Chinese). http://www.nhc.gov.cn/xcs/zhengcwj/202002/3b09b894ac9b4204a79db5b8912d4440/files/7260301a393845fc87fcf6dd52965ecb.pdf (accessed March 1 2020).

11. The Diagnosis and Treatment Plan for 2019-nCoV. 7th Trial Edition. http://www.nhc.gov.cn/xcs/zhengcwj/202003/46c9294a7dfe4cef80dc7f5912eb1989/files/ce3e6945832a438eaae415350a8ce964.pdf 
(accessed March 20 2020).

12. Contribution to Wuhan with SARS-CoV-2 IgG/lgM Assays. News release. http://www.szyhlo.com/en/news_detail.php? menuid=75\&id=125\&from=singlemessage\&isappinstalled=0 (accessed March 27, 2020).

13. Guan WJ, Ni ZY, Hu Y, et al. Clinical Characteristics of Coronavirus Disease 2019 in China. The New England journal of medicine 2020.

14. Metlay JP, Waterer GW, Long AC, et al. Diagnosis and Treatment of Adults with Community-acquired Pneumonia. An Official Clinical Practice Guideline of the American Thoracic Society and Infectious Diseases Society of America. American Journal of Respiratory and Critical Care Medicine 2019; 200(7): e45-e67.

15. Brook G, Brooks T, Coldron Y, et al. Chapter 27 - Physiotherapy in women's health. In: Porter SB, ed. Tidy's Physiotherapy (Fifteenth Edition): Churchill Livingstone; 2013: 605-35.

16. Xing Xie, Beihua kong, Duan. T. Obstetrics and Gynecology, the Ninth edition.: Beijing: People' s Medical Publishing House; 2018.

17. Maternal and Fetal Experts Committee CPSoOaG, Chinese Medical Doctor Association. , Obstetric Subgroup SoOaG, Chinese Medical Association. , Society of Perinatal Medicine CMA, Medicine. EBoCJoP. Proposed management of 2019-novel coronavirus infection during pregnancy and puerperium. Chinese Journal of Perinatal Medicine 2020; 23(02): 73-9.

18. Yang W, Lu J, Weng J, et al. Prevalence of diabetes among men and women in China. The New England journal of medicine 2010; 362(12): 1090-101.

19. Azulay CE, Pariente G, Shoham-Vardi I, Kessous R, Sergienko R, Sheiner E. Maternal anemia during pregnancy and subsequent risk for cardiovascular disease. J Matern Fetal Neonatal Med 2015; 28(15): 1762-5.

20. Knight M, Callaghan WM, Berg C, et al. Trends in postpartum hemorrhage in high resource countries: a review and recommendations from the International Postpartum Hemorrhage Collaborative Group. BMC Pregnancy Childbirth 2009; 9: 55.

21. Wang. WP, Sun. K, Chang. LW, et al. Pediatrics, the Ninth edition. Beijing: People's Medical Publishing House. ; 2008.

22. Benn PA, Schonhaut AG, Hsu LY. A high incidence of maternal cell contamination of amniotic fluid cell cultures. Am J Med Genet 1983 ; 14(2): 361-5.

23. Vojtek I, Dieussaert I, Doherty TM, et al. Maternal immunization: where are we now and how to move forward? Annals of Medicine 2018; 50(3): 193-208.

24. Chaouat G, Petitbarat M, Dubanchet S, Rahmati M, Ledée N. Tolerance to the Foetal Allograft? Am J Reprod Immunol 2010; 63(6): 62436.

25. Alfaraj SH, Al-Tawfiq JA, Memish ZA. Middle East Respiratory Syndrome Coronavirus (MERS-CoV) infection during pregnancy: Report of two cases \& review of the literature. J Microbiol Immunol Infect 2019; 52(3): 501-3.

26. Siston AM, Rasmussen SA, Honein MA, et al. Pandemic 2009 influenza $A(H 1 N 1)$ virus illness among pregnant women in the United States. JAMA 2010; 303(15): 1517-25.

27. Walls AC, Park Y-J, Tortorici MA, Wall A, McGuire AT, Veesler D. Structure, Function, and Antigenicity of the SARS-CoV-2 Spike Glycoprotein. Cell 2020.

28. Zheng Q, Duan T, Jin L. Single-cell RNA expression profiling of ACE2 and AXL in the human maternal-Fetal interface. Reprod Dev Med 2020.

29. Liu Y, Zhang J, Zhang R, et al. [Relationship between the immunohistopathological changes of hepatitis B virus carrier mothers' placentas and fetal hepatitis B virus infection]. Zhonghua Fu Chan Ke Za Zhi 2002; 37(5): 278-80.

30. Vyas AK, Negi P, Patra S, et al. Maternal Immunity Influences Vertical Transmission of Hepatitis B to Newborns. Hepatol Commun 2019; 3(6): 795-811.

\section{Tables}

Table 1. Clinical courses, imaging findings, treatment, and outcomes of PW-COVID-19 compared to GP-COVID-19 and the presence of the composite end point 


\begin{tabular}{|c|c|c|c|c|c|c|c|c|c|c|}
\hline \multirow[t]{2}{*}{ Variables } & \multirow{2}{*}{$\begin{array}{l}\text { PW-COVID-19 } \\
\quad(n=92)\end{array}$} & \multirow[t]{2}{*}{ GP-COVID-19 ${ }^{1}$} & \multirow{2}{*}{$\begin{array}{l}\text { P value } \\
2\end{array}$} & \multicolumn{3}{|c|}{ PW-COVID-19 (n=92) } & \multicolumn{4}{|c|}{ Presence of Composite End Point ${ }^{3}$} \\
\hline & & & & $\begin{array}{c}\text { The first } \\
\text { trimester }(n=9)\end{array}$ & $\begin{array}{l}\text { The second } \\
\text { trimester }(n=5)\end{array}$ & $\begin{array}{l}\text { The third } \\
\text { trimester }(n=78)\end{array}$ & Yes $(n=17)$ & No $(n=61)$ & $\begin{array}{c}\text { P value } \\
4\end{array}$ & $\begin{array}{c}\text { Mechanical } \\
\text { ventilation Group } \\
(n=2)^{5}\end{array}$ \\
\hline \multicolumn{11}{|l|}{ Demographics \& Epidemiology } \\
\hline Age, years & $\begin{array}{c}31.0(28.0- \\
33.0)\end{array}$ & $47.0(35.0-58.0)$ &. & $32.0(29.5-35.0)$ & $29.0(25.5-34.5)$ & $30.0(28.0-33.0)$ & $\begin{array}{c}30.0(37.5- \\
33.0)\end{array}$ & $\begin{array}{c}31.0(28.0- \\
34.0)\end{array}$ &. & 30 \\
\hline \multicolumn{11}{|l|}{ Epidemiologic history } \\
\hline Family cluster & $15 / 83(18.1 \%)$ &. & & $4 / 8(50 \%)$ & $3 / 5(60 \%)$ & $8 / 70(11.4 \%)$ & $1 / 13(7.7 \%)$ & $10 / 60(16.7 \%)$ & 0.84 & $1 / 2(50 \%)$ \\
\hline Linkage to Wuhan & $77 / 90(85.6 \%)$ &. & .. & $9 / 9(100 \%)$ & $2 / 5(40 \%)$ & $66 / 76(86.8 \%)$ & $16 / 16(100 \%)$ & $48 / 60(80 \%)$ & 0.00010 & $2 / 2(100 \%)$ \\
\hline Incubation period, days ${ }^{6}$ & $\begin{array}{l}8.0(6.75- \\
14.25)\end{array}$ & $4.0(2.0-7.0)$ & .. & $8.0(7.25-13.25)$ &. & $9.0(6.5-16.0)$ &. & $8.0(5.0-12.0)$ &.. & . \\
\hline \multicolumn{11}{|l|}{ Comorbidities } \\
\hline Any & $22 / 87(25.3 \%)$ & $261 / 1099(23.7 \%)$ & 0.85 & $1 / 8(12.5 \%)$ & $0 / 4(0 \%)$ & $21 / 75(28 \%)$ & $6 / 17(35.3 \%)$ & $14 / 61(23.0 \%)$ & 0.24 & $0 / 2(0 \%)$ \\
\hline Chronic obstructive pulmonary disease & $0 / 87(0 \%)$ & $12 / 1099(1.1 \%)$ & 0.67 & $0 / 8(0 \%)$ & $0 / 4(0 \%)$ & $0 / 75(0 \%)$ & $0 / 17(0 \%)$ & $0 / 61(0 \%)$ & .. & $0 / 2(0 \%)$ \\
\hline Chronic renal disease & $0 / 87(0 \%)$ & $8 / 1099(0.7 \%)$ & 0.91 & $0 / 8(0 \%)$ & $0 / 4(0 \%)$ & $0 / 75(0 \%)$ & $0 / 17(0 \%)$ & $0 / 61(0 \%)$ & .. & $0 / 2(0 \%)$ \\
\hline Coronary heart disease & $0 / 87(0 \%)$ & $27 / 1099(2.5 \%)$ & 0.27 & $0 / 8(0 \%)$ & $0 / 4(0 \%)$ & $0 / 75(0 \%)$ & $0 / 17(0 \%)$ & $0 / 61(0 \%)$ &. & $0 / 2(0 \%)$ \\
\hline Acute Respiratory Distress Syndrome & $0 / 87(0 \%)$ & $37 / 1099(3.4 \%)$ & 0.16 & $0 / 8(0 \%)$ & $0 / 4(0 \%)$ & $0 / 75(0 \%)$ & $0 / 17(0 \%)$ & $0 / 61(0 \%)$ & .. & $0 / 2(0 \%)$ \\
\hline Infectious diseases & $4 / 87(4.6 \%)$ &. & .. & $0 / 8(0 \%)$ & $0 / 4(0 \%)$ & $4 / 75(5.3 \%)$ & $0 / 17(0 \%)$ & $4 / 61(6.6 \%)$ & 0.68 & $0 / 2(0 \%)$ \\
\hline Hypothyroidism & $7 / 87(8.0 \%)$ &. &. & $0 / 8(0 \%)$ & $0 / 4(0 \%)$ & $7 / 75(9.3 \%)$ & $2 / 17(11.8 \%)$ & $5 / 61(8.2 \%)$ & 0.95 & $0 / 2(0 \%)$ \\
\hline \multicolumn{11}{|l|}{ Signs \& Symptoms - } \\
\hline Fever on admission $\left({ }^{\circ} \mathrm{C}\right)$ & $33 / 87(37.9 \%)$ & $473 / 1081(43.8 \%)$ & 0.35 & $5 / 8(62.5 \%)$ & $3 / 5(60 \%)$ & $25 / 74(33.8 \%)$ & $0 / 17(0 \%)$ & $28 / 59(47.5 \%)$ & 0.015 & $0 / 2(0 \%)$ \\
\hline Fever during hospitalization $\left({ }^{\circ} \mathrm{C}\right)$ & $19 / 74(25.7 \%)$ & $975 / 1099(88.7 \%)$ & $<0.0001$ & $0 / 7(0 \%)$ & $1 / 4(25 \%)$ & $18 / 63(28.6 \%)$ & $7 / 17(41.2 \%)$ & $12 / 52(23.1 \%)$ & 0.11 & $0 / 2(0 \%)$ \\
\hline Respiratory rate $>24$ breaths per min & $4 / 92(4.3 \%)$ &. &. & $0 / 9(0 \%)$ & $0 / 5(0 \%)$ & $4 / 78(5.1 \%)$ & $0 / 17(0 \%)$ & $3 / 61(4.9 \%)$ & 0.85 & $0 / 2(0 \%)$ \\
\hline Pulse $\geq 125$ beats per min & $1 / 92(1.1 \%)$ &. & .. & $0 / 9(0 \%)$ & $0 / 5(0 \%)$ & $1 / 78(1.3 \%)$ & $0 / 17(0 \%)$ & $1 / 61(1.6 \%)$ & 1 & $0 / 2(0 \%)$ \\
\hline \multicolumn{11}{|l|}{ Other signs and symptoms } \\
\hline Cough & $37 / 87(42.5 \%)$ & $745 / 1099(67.8 \%)$ & $<0.0001$ & $5 / 8(62.5 \%)$ & $4 / 5(80 \%)$ & $28 / 74(37.8 \%)$ & $6 / 17(35.3 \%)$ & $26 / 59(44.1 \%)$ & 0.92 & $1 / 2(50 \%)$ \\
\hline Sore throat & $7 / 87(8.0 \%)$ & $153 / 1099(13.9 \%)$ & 0.17 & $1 / 8(12.5 \%)$ & $0 / 5(0 \%)$ & $6 / 74(8.1 \%)$ & $1 / 17(5.9 \%)$ & $5 / 59(8.5 \%)$ & 1 & $0 / 2(0 \%)$ \\
\hline Fatigue & $13 / 87(14.9 \%)$ & $419 / 1099(38.1 \%)$ & $<0.0001$ & $3 / 8(37.5 \%)$ & $2 / 5(40 \%)$ & $8 / 74(10.8 \%)$ & $1 / 17(5.9 \%)$ & $10 / 59(16.9 \%)$ & 0.58 & $0 / 2(0 \%)$ \\
\hline Runny nose & $3 / 87(3.4 \%)$ &.. &.. & $0 / 8(0 \%)$ & $0 / 5(0 \%)$ & $3 / 74(4.1 \%)$ & $1 / 17(5.9 \%)$ & $2 / 59(3.4 \%)$ & 1 & $0 / 2(0 \%)$ \\
\hline Diarrhea & $1 / 87(1.1 \%)$ & $42 / 1099(3.8 \%)$ & 0.32 & $0 / 8(0 \%)$ & $0 / 5(0 \%)$ & $1 / 74(1.4 \%)$ & $0 / 17(0 \%)$ & $1 / 59(1.7 \%)$ & 1 & $0 / 2(0 \%)$ \\
\hline Myalgia & $2 / 87(2.3 \%)$ & $164 / 1099(14.9 \%)$ & 0.0019 & $0 / 8(0 \%)$ & $0 / 5(0 \%)$ & $2 / 74(2.7 \%)$ & $0 / 17(0 \%)$ & $2 / 59(3.4 \%)$ & 1 & $0 / 2(0 \%)$ \\
\hline Dyspnea & $1 / 87(1.1 \%)$ &. & .. & $0 / 8(0 \%)$ & $0 / 5(0 \%)$ & $1 / 74(1.4 \%)$ & $0 / 17(0 \%)$ & $0 / 59(0 \%)$ & .. & $0 / 2(0 \%)$ \\
\hline \multicolumn{11}{|l|}{ Radiologic findings } \\
\hline Abnormalities on chest CT & $81 / 91(89.0 \%)$ & $840 / 975(86.2 \%)$ & 0.55 & $8 / 9(88.9 \%)$ & $4 / 4(100 \%)$ & $69 / 78(88.5 \%)$ & $14 / 17(82.4 \%)$ & $55 / 60(91.7 \%)$ & 0.016 & $2 / 2(100 \%)$ \\
\hline Ground-glass opacity & $40 / 91(44.0 \%)$ & $550 / 975(56.4 \%)$ & 0.030 & $5 / 9(55.6 \%)$ & $2 / 4(50 \%)$ & $33 / 78(42.3 \%)$ & $9 / 17(52.9 \%)$ & $23 / 60(38.3 \%)$ & 0.081 & $0 / 2(0 \%)$ \\
\hline Local patchy shadowing & $54 / 91(59.3 \%)$ & $409 / 975(51.8 \%)$ & 0.0020 & $5 / 9(55.6 \%)$ & $3 / 4(75 \%)$ & $46 / 78(59 \%)$ & $8 / 17(47.1 \%)$ & $39 / 60(65.0 \%)$ & 0.74 & $1 / 2(50 \%)$ \\
\hline Interstitial abnormalities & $1 / 91(1.1 \%)$ & $143 / 975(14.7 \%)$ & 0.00054 & $0 / 9(0 \%)$ & $0 / 4(0 \%)$ & $1 / 78(1.3 \%)$ & $0 / 17(0 \%)$ & $1 / 60(1.7 \%)$ & 1 & $0 / 2(0 \%)$ \\
\hline \multicolumn{11}{|l|}{ Degree of severity } \\
\hline \multicolumn{11}{|l|}{ Severity based on Chinese guidelines } \\
\hline Mild & $10 / 92(10.9 \%)$ &. &. & $0 / 9(0 \%)$ & $1 / 5(20 \%)$ & $9 / 78(11.5 \%)$ & $3 / 17(17.6 \%)$ & $6 / 61(9.8 \%)$ & 0.55 & $0 / 2(0 \%)$ \\
\hline Moderate & $76 / 92(82.6 \%)$ & .. & .. & $8 / 9(88.9 \%)$ & $4 / 5(80 \%)$ & $64 / 78(82.1 \%)$ & $13 / 17(76.5 \%)$ & $51 / 61(83.6 \%)$ & 0.034 & $1 / 2(0 \%)$ \\
\hline Severe & $5 / 92(5.4 \%)$ &. &. & $0 / 9(0 \%)$ & $0 / 5(0 \%)$ & $5 / 78(6.4 \%)$ & $0 / 17(0 \%)$ & $4 / 61(6.6 \%)$ & 0.68 & $0 / 2(0 \%)$ \\
\hline Critical & $1 / 92(1.1 \%)$ &. &. & $1 / 9(11.1 \%)$ & $0 / 5(0 \%)$ & $0 / 78(0 \%)$ & $1 / 17(5.9 \%)$ & $0 / 61(0 \%)$ & 0.49 & $1 / 2(0 \%)$ \\
\hline \multicolumn{11}{|c|}{$\begin{array}{l}\text { Severity based on ATS guidelines for community- } \\
\text { acquired pneumonia }\end{array}$} \\
\hline Severe & $2 / 92(2.2 \%)$ & $172 / 1099(15.7 \%)$ & $<0.0001$ &. & .. & .. & .. &. &. & . \\
\hline Nonsevere & $90 / 92(97.8 \%)$ & $926 / 1099(84.3 \%)$ & $<0.0001$ & .. & .. & .. &. &. &. & . \\
\hline \multicolumn{11}{|l|}{ Treatment } \\
\hline \multicolumn{11}{|l|}{ Treatment measures } \\
\hline Admission to intensive care unit & $17 / 78(21.8 \%)$ & $55 / 1099(5.0 \%)$ & $<0.0001$ & $1 / 6(16.7 \%)$ & $0 / 4(0 \%)$ & $16 / 68(23.5 \%)$ &. &. & .. & $2 / 2(100 \%)$ \\
\hline Oxygen therapy & $46 / 78(59.0 \%)$ & $454 / 1099(41.3 \%)$ & 0.0034 & $5 / 6(83.3 \%)$ & $2 / 4(50 \%)$ & $39 / 68(57.4 \%)$ & $13 / 17(76.5 \%)$ & $33 / 61(54.1 \%)$ & 0.0035 & $2 / 2(100 \%)$ \\
\hline
\end{tabular}




\begin{tabular}{|c|c|c|c|c|c|c|c|c|c|c|}
\hline Antibiotic therapy & 73/78(93.6\%) & 637/1099(58.0\%) & $<0.0001$ & $6 / 6(100 \%)$ & $4 / 4(100 \%)$ & $63 / 68(92.6 \%)$ & $17 / 17(100 \%)$ & $56 / 61(91.8 \%)$ & 0.00016 & $2 / 2(100 \%)$ \\
\hline Antiviral therapy & $62 / 78(79.5 \%)$ & 393/1099(35.8\%) & $<0.0001$ & $6 / 6(100 \%)$ & $4 / 4(100 \%)$ & $52 / 68(76.5 \%)$ & $12 / 17(70.6 \%)$ & $50 / 61(82.0 \%)$ & 0.089 & $2 / 2(100 \%)$ \\
\hline Systemic glucocorticoids & $5 / 78(6.4 \%)$ & 204/1099(18.6\%) & 0.010 & $0 / 6(0 \%)$ & $0 / 4(0 \%)$ & $5 / 68(7.4 \%)$ & $1 / 17(5.9 \%)$ & $4 / 61(6.6 \%)$ & 1 & $0 / 2(0 \%)$ \\
\hline \multicolumn{11}{|l|}{ Mechanical ventilation } \\
\hline Invasive & $1 / 78(1.3 \%)$ & $25 / 1099(2.3 \%)$ & 0.86 & $1 / 6(16.7 \%)$ & $0 / 4(0 \%)$ & $0 / 68(0 \%)$ & .. & .. & .. & $1 / 2(50 \%)$ \\
\hline Noninvasive & $2 / 78(2.6 \%)$ & $56 / 1099(5.1 \%)$ & 0.47 & $1 / 6(16.7 \%)$ & $0 / 4(0 \%)$ & $1 / 68(1.5 \%)$ & .. & .. & .. & $2 / 2(100 \%)$ \\
\hline Use of intravenous immune globulin & $3 / 78(3.8 \%)$ & $144 / 1099(13.1 \%)$ & 0.027 & $0 / 6(0 \%)$ & $2 / 4(50 \%)$ & $1 / 68(1.5 \%)$ & $0 / 17(0 \%)$ & $3 / 61(4.9 \%)$ & 0.85 & $0 / 2(0 \%)$ \\
\hline Median length of hospital stay, days & $\begin{array}{c}9.50(5.25- \\
15.00)\end{array}$ & $12.0(10.00-14.00)$ & .. & .. & $10.50(6.75-15.75)$ & $9.50(5.00-15.50)$ & $\begin{array}{c}9.00(3.00- \\
18.00)\end{array}$ & $\begin{array}{c}9.50(6.00- \\
15.50)\end{array}$ & .. & " \\
\hline \multicolumn{11}{|l|}{ Outcomes } \\
\hline Discharge from hospital & $85 / 92(92.4 \%)$ & $55 / 1099(5.0 \%)$ & $<0.0001$ & $7 / 9(77.8 \%)$ & $5 / 5(100 \%)$ & 73/78(93.6\%) & $15 / 17(88.2 \%)$ & $58 / 61(95.1 \%)$ & 0.0052 & $1 / 2(50 \%)$ \\
\hline Hospitalization & $7 / 92(7.6 \%)$ & 1029/1099(93.6\%) & $<0.0001$ & $2 / 9(22.2 \%)$ & $0 / 5(0 \%)$ & $5 / 78(6.4 \%)$ & $2 / 17(11.8 \%)$ & $3 / 61(4.9 \%)$ & 0.61 & $1 / 2(50 \%)$ \\
\hline Death & $0 / 92(0 \%)$ & 15/1099(1.4\%) & 0.52 & $0 / 9(0 \%)$ & $0 / 5(0 \%)$ & $0 / 78(0 \%)$ & $0 / 17(0 \%)$ & $0 / 61(0 \%)$ & .. & $0 / 2(0 \%)$ \\
\hline
\end{tabular}

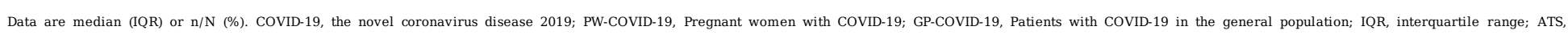
American Thoracic Society

1. The data of GP-COVID-19 was quoted from Guan WJ, et al. ${ }^{1}$. which was currently the largest cases reported on COVID-19

2. P value was calculated between PW-COVID-19 and GP-COVID-19.

3. The composite end point was admission to an intensive care unit (ICU), the use of mechanical ventilation, or death.

4. P value was calculated between the presence of composite end point group and the absenoe of composite end point group.

5. The pregnant women received mechanical ventilation were listed separately. 1 patient used both invasive and noninvasive mechanical ventilation.

6. Data regarding the incubation period included 22 patients.

Table 2 Epidemiology, clinical characteristics, treatment and outcomes of PW-COVID-19 compared to SARS, MERS, Zika virus infection, and H1N1 infection in pregnant women 


\begin{tabular}{|c|c|c|c|c|c|c|c|c|c|}
\hline Variable & $\begin{array}{l}\text { PW-COVID- } \\
19(n=92)\end{array}$ & $\begin{array}{l}\text { Pregnant women with } \\
\text { SARS }(\mathrm{n}=12)^{1}\end{array}$ & $\begin{array}{l}\text { P value } \\
\text { Covid-19 } \\
\text { vs SARS }{ }^{2} \\
\text { in pregnant } \\
\text { women }\end{array}$ & $\begin{array}{l}\text { Pregnant women with } \\
\text { MERS }(n=11)^{3}\end{array}$ & $\begin{array}{l}\text { P value } \\
\text { COVID-19 vs } \\
\text { MERS }{ }^{4} \\
\text { in pregnant } \\
\text { women }\end{array}$ & $\begin{array}{l}\text { Pregnant women with Zika virus } \\
\text { infection }(\mathrm{n}=1259)^{5}\end{array}$ & $\begin{array}{l}\text { P value } \\
\text { Covid-19 } \\
\text { vs Zika }{ }^{6} \\
\text { in pregnant } \\
\text { women }\end{array}$ & $\begin{array}{l}\text { Pregnant women with } \\
\text { H1N1 infection }{ }^{7}\end{array}$ & $\begin{array}{l}\text { P value } \\
\text { Covid-19 vs } \\
\text { H1N1 }{ }^{8} \\
\text { in pregnant } \\
\text { women }\end{array}$ \\
\hline \multicolumn{10}{|l|}{ Epidemiology } \\
\hline Family cluster & $15 / 83(18.1 \%)$ & $3 / 12(25 \%)$ & 0.86 & $2 / 11(18.2 \%)$ & 1 & .. & .. & .. & .. \\
\hline \multicolumn{10}{|l|}{ Signs and Symptoms } \\
\hline Fever ${ }^{11}$ & $37 / 87(42.5 \%)$ & $12 / 12(100 \%)$ & 0.00062 & $7 / 11(81.8 \%)$ & 0.32 & .. & .. & $33 / 34(97 \%)^{12}$ & $<0.0001$ \\
\hline Cough & $37 / 87(42.5 \%)$ & $9 / 12(75 \%)$ & 0.071 & $7 / 11(63.6 \%)$ & 0.32 &. & .. & $32 / 34(94 \%)^{12}$ & $<0.0001$ \\
\hline Fatigue & $13 / 87(14.9 \%)$ &. &. & $1 / 11(9.1 \%)$ & 0.95 & .. & .. &. &. \\
\hline Runny nose & $3 / 87(3.4 \%)$ & $3 / 12(25 \%)$ & 0.022 & $1 / 11(9.1 \%)$ & 0.93 & .. & .. &. & .. \\
\hline Diarrhea & $1 / 87(1.1 \%)$ & $2 / 12(17 \%)$ & 0.041 & .. & .. & .. & .. & $4 / 34(12 \%)^{12}$ & 0.033 \\
\hline Myalgia & $2 / 87(2.3 \%)$ & $12 / 12(100 \%)$ & $<0.0001$ & $3 / 11(27.3 \%)$ & 0.0048 & .. & .. & $12 / 34(35 \%)^{12}$ & $<0.0001$ \\
\hline Dyspnea & $1 / 87(1.1 \%)$ &. &. & $6 / 11(54.5 \%)$ & $<0.0001$ &. & .. & .. & .. \\
\hline CXR or CT evidence & $81 / 91(89.0 \%)$ & $12 / 12(100 \%)$ & 0.49 & .. & .. & .. & .. & .. & .. \\
\hline \multicolumn{10}{|l|}{ Treatment } \\
\hline $\begin{array}{c}\text { Admission to } \\
\text { intensive care unit }\end{array}$ & $17 / 78(21.8 \%)$ & $6 / 12(50 \%)$ & 0.084 & $7 / 11(63.6 \%)$ & 0.010 & .. & .. & $115 / 465(24.7 \%)^{10}$ & 0.68 \\
\hline Oxygen therapy & $46 / 78(59.0 \%)$ & .. &. &. & .. & .. & .. & .. & .. \\
\hline $\begin{array}{c}\text { Systemic } \\
\text { glucocorticoids }\end{array}$ & $5 / 78(6.4 \%)$ & $11 / 12(91.7 \%)$ & $<0.0001$ & .. &. & .. & .. & .. & .. \\
\hline $\begin{array}{l}\text { Mechanical } \\
\text { ventilation }\end{array}$ & $2 / 78(2.6 \%)$ & $4 / 12(33 \%)$ & 0.00079 & $5 / 11(45.5 \%)$ & $<0.0001$ & .. &. & $77 / 409(18.8 \%)^{10}$ & 0.00067 \\
\hline \multicolumn{10}{|l|}{ Outcome } \\
\hline Maternal Death & $0 / 92(0 \%)$ & $3 / 12(25 \%)$ & $<0.0001$ & $3 / 11(27.3 \%)$ & $<0.0001$ & .. & .. & $30 / 692(4.3 \%)^{10}$ & 0.08 \\
\hline Preterm delivery & $21 / 78(26.9 \%)$ & $4 / 5(80 \%)$ & 0.045 & $2 / 11(18.2 \%)$ & 0.80 & $113 / 1195(9.5 \%)$ & $<0.0001$ & $51 / 169(30.2 \%)^{10}$ & 0.71 \\
\hline Fetal death & $0 / 92(0 \%)$ & .. &. & $3 / 11(27.3 \%)$ & $<0.0001$ & $5 / 1195(0.4 \%)$ & 1 & .. & .. \\
\hline cs & $66 / 92(71.7 \%)$ & $4 / 12(33.3 \%)$ & 0.019 & $4 / 11(36.4 \%)$ & 0.042 & .. & .. & $109 / 585(18.6 \%)^{10}$ & $<0.0001$ \\
\hline Vaginal delivery & $9 / 92(9.8 \%)$ & $1 / 12(8.3 \%)$ & 1 & $4 / 11(36.4 \%)$ & 0.043 & .. & .. & $79 / 585(13.5 \%)^{10}$ & 0.41 \\
\hline
\end{tabular}

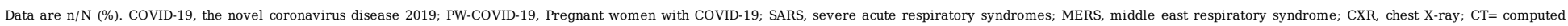
tomography; CS, Cesarean section;

1. The data of pregnant women with SARS was quoted from Wong SF, et al. ${ }^{2}$.

2. P value was calculated between PW-COVID-19 and pregnant women with SARS

3. The data of pregnant women with MERS was quoted from Alfaraj SH, et al. ${ }^{3}$.

4. P value was calculated between PW-COVID-19 and pregnant women with MERS.

5. The data of pregnant women with Zika virus infection was quoted from Ocampo Canas JA, et al. ${ }^{4}$.

6. P value was calculated between PW-COVID-19 and pregnant women with Zika virus infection.

7. The data of pregnant women with H1N1 infection was quoted from two studies $5,6$.

8. P value was calculated between PW-COVID-19 and pregnant women with H1N1 infection.

9. The age of pregnant women with Zika virus infection $(n=1259)$ was represented as mean \pm SD

10. The data was quoted from Siston AM, et al. ${ }^{5}$.

11. Fever was defined as an axillary temperature of $37.3^{\circ} \mathrm{C}$ or higher

12. The data was quoted from Jamieson DJ, et al. 6 . 


\begin{tabular}{|c|c|c|c|c|c|c|c|c|c|}
\hline \multirow[t]{3}{*}{ Variable } & \multirow{2}{*}{\multicolumn{2}{|c|}{$\begin{array}{l}\text { All }(n=92) \\
\text { vs reference range }\end{array}$}} & \multirow{2}{*}{\multicolumn{2}{|c|}{$\begin{array}{c}\text { The first trimester }(\mathrm{n}=9) \\
\text { vs reference range }\end{array}$}} & \multirow{2}{*}{\multicolumn{2}{|c|}{$\begin{array}{c}\text { The second trimester }(\mathrm{n}=5) \\
\text { vs reference range }\end{array}$}} & \multirow{2}{*}{\multicolumn{2}{|c|}{$\begin{array}{c}\text { The third trimester }(\mathrm{n}=78) \\
\text { vs reference range }\end{array}$}} & \multirow[t]{3}{*}{ Reference range } \\
\hline & & & & & & & & & \\
\hline & Data & P value ${ }^{1}$ & Data & P value $^{2}$ & Data & Pvalue ${ }^{3}$ & Data & $P$ value ${ }^{4}$ & \\
\hline Suspected duration of virus exposure, days & $7(0-27)$ & .. & $30(14.5-43.5)$ & .. & $32(22.5-43.5)$ & .. & $1(0-14)$ & .. & .. \\
\hline \multicolumn{10}{|l|}{ Weight gain in the whole pregnancy $(\mathrm{kg})(\mathrm{n}=58)^{6}$} \\
\hline $\mathrm{BM} \sqcap 18.5(\mathrm{n}=0)$ & .. & .. & .. & .. & .. & .. & .. & .. & $12.5-18$ \\
\hline \multicolumn{10}{|l|}{ BMI: $18.5-24.9(\mathrm{n}=8)$} \\
\hline Decreased & $4 / 8(50 \%)$ & .. & .. & .. & .. & . & $4 / 8(50 \%)$ & .. & $11.5-16$ \\
\hline Increased & $0 / 8(0 \%)$ & .. & .. & .. & .. & .. & $0 / 8(0 \%)$ & .. & $11.5-16$ \\
\hline \multicolumn{10}{|l|}{ BMI :25.0-29.9(n=40) } \\
\hline Decreased & $2 / 40(5 \%)$ & .. & .. & .. & .. & .. & $2 / 40(5 \%)$ & .. & $7-11.5$ \\
\hline Increased & $17 / 40(42.5 \%)$ & .. & .. & .. & .. & .. & $17 / 40(42.5 \%)$ & .. & $7-11.5$ \\
\hline \multicolumn{10}{|l|}{ BMI $\geq 30(n=10)$} \\
\hline Decreased & $1 / 10(10 \%)$ & .. & .. & .. & .* & .. & $1 / 10(10 \%)$ & .. & $5-9$ \\
\hline Increased & $3 / 10(30 \%)$ &. & .. & .. & .. & .. & $3 / 10(30 \%)$ & .. & $5-9$ \\
\hline \multicolumn{10}{|l|}{ Comorbidity \& Complication } \\
\hline Hypertensive disorders of pregnancy & $9 / 87(10.3 \%)$ & 0.54 & $1 / 8(12.5 \%)$ & 0.67 & $0 / 5(0 \%)$ & 0.50 & $8 / 75(10.7 \%)$ & 0.49 & $5-12 \%^{7}$ \\
\hline Gestational diabetes mellitus & $7 / 87(8.0 \%)$ & 0.011 & $0 / 8(0 \%)$ & 0.16 & $0 / 5(0 \%)$ & 0.29 & $7 / 75(9.3 \%)$ & 0.043 & $17.5 \%-18.9 \%^{8}$ \\
\hline Anemia & $15 / 87(17.2 \%)$ & 0.057 & $0 / 8(0 \%)$ & 0.076 & $0 / 5(0 \%)$ & 0.19 & $15 / 75(20 \%)$ & 0.23 & $25.9 \%^{9}$ \\
\hline Postpartum hemorrhage & $0 / 87(0 \%)$ & 0.050 & .. & 0.54 & .. & 0.65 & $0 / 75(0 \%)$ & 0.071 & $3-5 \%^{10}$ \\
\hline Puerperal infection & $0 / 87(0 \%)$ & 0.015 & .. & 0.45 & .. & 0.57 & $0 / 75(0 \%)$ & 0.026 & $6 \%^{7}$ \\
\hline \multicolumn{10}{|l|}{ Maternal outcome } \\
\hline Induced abortion & $7 / 92(7.6 \%)$ & $<0.0001$ & $7 / 9(77.8 \%)$ & $<0.0001$ & $0 / 5(0 \%)$ & 0.79 & .. & 0.28 & $14.6 \%{ }^{11}$ \\
\hline Preterm delivery & $21 / 78(26.9 \%)$ & $<0.0001$ & .. & 0.30 & .* & 0.44 & $21 / 78(26.9 \%)$ & $<0.0001$ & $10.6 \%^{12}$ \\
\hline Stillbirth & $1 / 92(1.1 \%)$ & 0.60 & .. & 0.68 & $1 / 5(20 \%)^{13}$ & 0.0025 & $0 / 78(0 \%)$ & 0.23 & $18.4 \%{ }^{14}$ \\
\hline $\operatorname{cs}^{15}$ & $66 / 75(88 \%)^{15}$ & .. & .. & .. & .. & .. & $66 / 75(88 \%)$ & .. & .. \\
\hline Vaginal delivery & $9 / 75(12 \%)$ & .. & .. & .. & .. & .. & $9 / 75(12 \%)$ & .. & . \\
\hline \multicolumn{10}{|l|}{ Antenatal care $(\mathrm{n}=22)$} \\
\hline Suspected duration of virus exposure until last inspection, days ${ }^{16}$ & $3(1-8)$ & .* & .* & .. & $22(12.5-31.5)$ & .. & $2(1-6)$ & .. & .* \\
\hline \multicolumn{10}{|l|}{ Blood pressure } \\
\hline Systolic pressure & $118.71 \pm 12.68$ & $<0.0001$ & $114 \pm 14.51$ & $<0.0001$ & $117.75 \pm 5.19$ & $<0.0001$ & $119.16 \pm 13.05$ & $<0.0001$ & $90-140^{7}$ \\
\hline diastolic pressure & $77.12 \pm 10.43$ & $<0.0001$ & $74 \pm 7.35$ & $<0.0001$ & $74.75 \pm 4.99$ & $<0.0001$ & $77.56 \pm 10.96$ & $<0.0001$ & $60-90^{7}$ \\
\hline \multicolumn{10}{|l|}{ Fundal height } \\
\hline $32 \mathrm{~W}-35+6 \mathrm{~W}$ & $33.33 \pm 3.51$ & $<0.0001$ & .. & .. & .. & .. & $33.33 \pm 3.51$ & $<0.0001$ & $30.5(25.5-34.5)^{7}$ \\
\hline $36 \mathrm{~W}-40 \mathrm{~W}$ & $34.12 \pm 1.33$ & $<0.0001$ & .. & .. & .. & .. & $34.12 \pm 1.33$ & $<0.0001$ & $32.5(29.8-35.3)^{7}$ \\
\hline \multicolumn{10}{|l|}{ Abdominal circumference } \\
\hline $32 \mathrm{~W}-35+6 \mathrm{~W}$ & $109.67 \pm 3.79$ & .. & .. &. & .. & .. & $109.67 \pm 3.79$ & .. & .. \\
\hline $36 \mathrm{~W}-40 \mathrm{~W}$ & $102.38 \pm 6.37$ & .. & .. & .. & .. & .. & $102.38 \pm 6.37$ & .. & .. \\
\hline Fetal heart rate (bpm) & $144 \pm 5.74$ & $<0.0001$ & .. & .. & $148.75 \pm 6.99$ & 0.012 & $143.52 \pm 5.30$ & $<0.0001$ & $110-160$ \\
\hline
\end{tabular}

Data are median (IQR), mean \pm SD, or n/N (\%). COVID-19, the novel coronavirus disease 2019; PW-COVID-19, Pregnant women with COVID-19; IQR,interquartile range; CS, Cesarean section;

1. P value was calculated between PW-COVID-19 and reference range of pregnant women in the general population.

2. $\mathrm{P}$ value was calculated between the first trimester group in PW-COVID-19 and reference range of pregnant women in general population.

3. P value was calculated between the second trimester group in PW-COVID-19 and reference range of pregnant women in general population.

4. P value was calculated between the third trimester group in PW-COVID-19 and reference range of pregnant women in general population.

5. The reference range of pregnant women in the general population was listed ${ }^{7-14}$

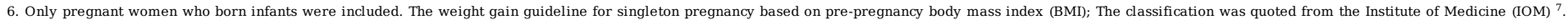


7. The data was quoted from Obstetrics and Gynecology, the Ninth edition: Beijing: People' s Medical Publishing House. ${ }^{8}$.

8. The data was quoted from Yang, W. et al. ${ }^{9}$.

9. The data was quoted from Azulay CE, et al. ${ }^{10}$

10. The data was quoted from Knight $M$, et al. ${ }^{11}$.

11. The data was quoted from Jones RK, et al. ${ }^{12}$

12. The data was quoted from Chawanpaiboon, S. et al. ${ }^{13}$.

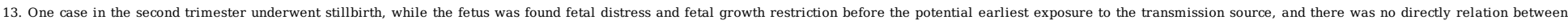
the fetal death and COVID-19.

14. The data was quoted from Chen D, et al. ${ }^{14}$

15. Of 78 PW-COVID-19 in the third trimester, 75 patients delivered by CS or vaginal delivery, and three patients were still in pregnancy.

16. The median suspected duration of virus exposure was calculated from 25 PW-COVID-19 who undertook antenatal care after disease confirmation.

Table 4 Perinatal and neonatal outcomes of PW-COVID-19 $(n=78)^{1}$ 


\begin{tabular}{|c|c|c|c|c|c|c|c|c|c|c|c|c|c|}
\hline \multirow[t]{3}{*}{ Variables } & \multicolumn{2}{|c|}{ All $(n=78)$} & \multicolumn{5}{|c|}{ Comparison between preterm and term infants } & \multicolumn{5}{|c|}{ Comparison between Vaginal delivery and CS } & \multirow{3}{*}{$\begin{array}{l}\text { Reference } \\
\text { range } 10\end{array}$} \\
\hline & \multirow[b]{2}{*}{ Data } & \multirow[b]{2}{*}{$\begin{array}{l}\text { P value with } \\
\text { Reference } \\
\text { range }^{3}\end{array}$} & \multicolumn{2}{|c|}{ Preterm infants $(\mathrm{n}=21)$} & \multicolumn{2}{|c|}{ Term infants(n=57) ${ }^{2}$} & \multirow{2}{*}{$\begin{array}{c}\mathrm{P} \\
\text { value } \\
6\end{array}$} & \multicolumn{2}{|c|}{ Vaginal delivery $(\mathrm{n}=9)$} & \multicolumn{2}{|c|}{ CS $(n=69)$} & \multirow{2}{*}{$\begin{array}{c}\mathrm{P} \\
\text { value } \\
9\end{array}$} & \\
\hline & & & Data & $\begin{array}{l}\text { P value } \\
\text { with } \\
\text { referenœ } \\
\text { range } 4\end{array}$ & Data & $\begin{array}{l}\text { P value } \\
\text { with } \\
\text { reference } \\
\text { range }^{5}\end{array}$ & & Data & $\begin{array}{l}\text { P value } \\
\text { with } \\
\text { reference } \\
\text { range }^{7}\end{array}$ & Data & $\begin{array}{l}\text { P value } \\
\text { with } \\
\text { referenœ } \\
\text { range }^{8}\end{array}$ & & \\
\hline \multicolumn{14}{|l|}{ Baseline information } \\
\hline \multicolumn{14}{|l|}{$\begin{array}{l}\text { Average value of growth index (0- } \\
<1 \text { month) } \mathbb{N}=680\end{array}$} \\
\hline \multicolumn{14}{|l|}{ Weight(g) } \\
\hline Male & $3110.74 \pm 492.82$ & $<0.0001$ & $2641.25 \pm 584.84$ & $<0.0001$ & $3255.19 \pm 364.12$ & 0.004 &.. & $3326.88 \pm 448.27$ & 0.64 & $3044.23 \pm 494.75$ & $<0.0001$ &. & $3400 \pm 400$ \\
\hline Female & $2976.67 \pm 543.99$ & $<0.0001$ & $2610 \pm 727.36$ & 0.0003 & $3114.17 \pm 394.16$ & 0.00077 &. &. & 1.0 & $3009.69 \pm 518.00$ & $<0.0001$ &. & $3300 \pm 400$ \\
\hline \multicolumn{14}{|l|}{ Height(cm) } \\
\hline Male & $49.15 \pm 1.70$ & $<0.0001$ & $47.71 \pm 3.15$ & 0.0009 & $49.54 \pm 0.76$ & $<0.0001$ &. & $49.875 \pm 0.64$ & 0.039 & $48.92 \pm 1.87$ & $<0.0001$ &. & $50.4 \pm 1.6$ \\
\hline Female & $48.72 \pm 2.34$ & 0.00011 & $47.33 \pm 3.39$ & 0.0033 & $49.26 \pm 1.57$ & 0.012 &.. &. &. & $48.77 \pm 2.36$ & 0.00060 &. & $49.8 \pm 1.6$ \\
\hline \multicolumn{14}{|l|}{ Apgar score $(n=66)$} \\
\hline $1 \mathrm{~min}$ & $8.76 \pm 0.91$ & 0.014 & $8.65 \pm 0.86$ & 0.43 & $8.80 \pm 0.93$ & 0.018 &.. & $9 \pm 1.20$ & 0.25 & $8.74 \pm 0.88$ & 0.027 &. & $7-10$ \\
\hline $5 \mathrm{~min}$ & $9.50 \pm 0.93$ & $<0.0001$ & $9.53 \pm 0.51$ & $<0.0001$ & $9.49 \pm 0.54$ & $<0.0001$ &.. & $9.5 \pm 0.76$ & 0.0043 & $9.51 \pm 0.50$ & $<0.0001$ &. & $7-10$ \\
\hline \multicolumn{14}{|l|}{ Feeding regimens } \\
\hline Artificial feeding ${ }^{12}$ & $54 / 61(88.52 \%)$ &. & $15 / 17(88.24 \%)$ &. & $39 / 44(88.64 \%)$ &. & 1.0 & 6/9(66.67\%) &. & $48 / 52(92.31 \%)$ &. & 0.10 &. \\
\hline Breast feeding & $1 / 61(1.64 \% \square$ &. & $0 / 17(0 \%)$ &. & $1 / 44(2.27 \%)$ &. & 1.0 & $1 / 9(11.1 \%)$ &. & $0 / 52(0 \%)$ &. &. &. \\
\hline Mixed mode & 6/61(9.84\% &.. & $2 / 17(11.76 \%)$ &. & $4 / 44(9.09 \%)$ &. & 1.0 & $2 / 9(22.2 \%)$ &. & $4 / 52(7.69 \%)$ &. & 0.46 &. \\
\hline \multicolumn{14}{|l|}{ Abnormal fetus and appendages } \\
\hline \multicolumn{13}{|l|}{ Causes of Fetal distress } & $2.7-38.5$ \\
\hline Pregnant with anemia & $4 / 18(22.23 \%)$ &. & $2 / 7(28.57 \%)$ &. & $2 / 11(18.2 \%)$ &. & 1.0 & $0 / 1(0 \%)$ &. & $4 / 17(23.53 \%)$ &.. & 0.31 &. \\
\hline $\begin{array}{l}\text { Gestational diabetes } \\
\text { mellitus }\end{array}$ & $2 / 18(11.12 \%)$ &. & $1 / 7(14.29 \%)$ &. & $1 / 11(9.1 \%)$ &. & 1.0 & $1 / 1(100 \%)$ &. & $1 / 17(5.88 \%)$ &. & 1.0 &. \\
\hline $\begin{array}{l}\text { Umbilical cord } \\
\text { abnormality }\end{array}$ & $1 / 18(5.56 \%)$ &. & $1 / 7(14.29 \%)$ &. & $0 / 11(0 \%)$ &. &. & $0 / 1(0 \%)$ &. & $1 / 17(5.88 \%)$ &. & 1.0 &. \\
\hline Amniotic fluid pollution & $2 / 18(11.12 \%)$ &. & $0 / 7(0 \%)$ & .. & $2 / 11(18.2 \%)$ &. &. & $0 / 1(0 \%)$ &. & $2 / 17(11.76 \%)$ &. & 0.77 &. \\
\hline Plaœntal abruption & $0 / 18(0 \%)$ & .. & $0 / 7(0 \%)$ & .. & $0 / 11(0 \%)$ &. &. & $0 / 1(0 \%)$ &. & $0 / 17(0 \%)$ &. &. & 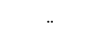 \\
\hline $\begin{array}{l}\text { Multiple factors } \\
\text { (HypertensivedPregnant } \\
\text { with asthma and above } \\
\text { causes) }\end{array}$ & $7 / 18(38.89 \%)$ &. & $3 / 7(28.57 \%)$ &.. & $4 / 11(36.3 \%)$ &. & 0.70 & $0 / 1(0 \%)$ &. & $7 / 17(41.18 \%)$ &. & 0.074 &. \\
\hline No obvious incentive & $2 / 18(11.12 \%)$ &. & $0 / 7(0 \%)$ &. & $2 / 11(18.2 \%)$ &. & 0.62 & $0 / 9(0 \%)$ &. & $2 / 17(11.76 \%)$ &. & 0.77 &. \\
\hline $\begin{array}{l}\text { Premature rupture of } \\
\text { membrane (singleton) }\end{array}$ & $7 / 72(9.7 \%)$ & 0.00052 & $4 / 21(19.05 \%)$ & $<0.0001$ & $3 / 51(5.88 \%)$ & 0.20 & 0.20 & $1 / 9(11.1 \%)$ & 0.15 & 6/63(9.53\%) & 0.0010 & 1.0 & $2-4$ \\
\hline \multicolumn{14}{|l|}{$\begin{array}{l}\text { Cause of premature rupture } \\
\text { of membrane }\end{array}$} \\
\hline Injury & $0 / 7(0 \%)$ &. & $0 / 4(0 \%)$ &. & $0 / 3(0 \%)$ & .. &. & $0 / 3(0 \%)$ &. & $0 / 6(0 \%)$ &. &. & . \\
\hline Other infections & $1 / 7(14.29 \%)$ &. & $1 / 4(25 \%)$ &. & $0 / 3(0 \%)$ &. & 1.0 & $0 / 3(0 \%)$ &. & $1 / 6(16.67 \%)$ &. & 1.0 &. \\
\hline No obvious incentive & $6 / 7(85.71 \%)$ &. & $3 / 4(75 \%)$ &. & $3 / 3(100 \%)$ &. & 1.0 & $1 / 3(33.3 \%)$ &. & $5 / 6(83.33 \%)$ &. & 0.45 &. \\
\hline $\begin{array}{l}\text { Premature rupture of } \\
\text { membrane (Twins) }\end{array}$ & $1 / 3(33.3 \%)$ & $<0.0001$ &.. &. &. &. &.. &. &. &. &. & . & $7-20$ \\
\hline Cord entanglement ${ }^{13}$ & $13 / 78(16.67 \%)$ & 0.050 & $4 / 21(19.05 \%)$ & 0.17 & $9 / 57(15.79 \%)$ & 0.15 & 1.0 & 3/9(33.3\%) & 0.020 & $10 / 69(14.49 \%)$ & 0.21 & 0.34 & 20 \\
\hline Amniotic fluid pollution ${ }^{13}$ & $10 / 78(12.82 \%)$ &.. & $4 / 21(19.05 \%)$ &. & $6 / 57(10.53 \%)$ &. & 0.54 & $0 / 9(0 \%)$ & 0.76 & $10 / 69(14.49 \%)$ &.. & 0.49 & $1 \%^{14}$ \\
\hline Placental abruption 13 & $2 / 78(2.56 \%)$ & 0.17 & $1 / 21(4.76 \%)$ & 0.083 & $1 / 57(1.75 \%)$ & 0.57 & 1.0 & $0 / 9(0 \%)$ & 0.76 & $2 / 69(2.90 \%)$ & 0.11 & 1.0 & $1 \%$ \\
\hline Atrial septal defect (ASD) ${ }^{13}$ & $3 / 78(3.85 \%)$ & $<0.0001$ & $0 / 21(0 \%)$ & 0.91 & $3 / 57(5.26 \%)$ & $<0.0001$ & 0.68 & $0 / 9(0 \%)$ & 0.94 & $3 / 69(4.35 \%)$ & $<0.0001$ & 1.0 & $0.3 \%$ o- $1 \%$ \\
\hline
\end{tabular}




\begin{tabular}{|c|c|c|c|c|c|c|c|c|c|c|c|c|c|}
\hline $\begin{array}{l}\text { Hyperbilirubinemia -no./total } \\
\text { no. }(\%)^{15}\end{array}$ & $20 / 62(31.67 \%)$ & $<0.0001$ & $5 / 17(29.41 \%)$ & $<0.0001$ & $15 / 45(33.33 \%)$ & $<0.0001$ & 1.0 & $2 / 9(22.2 \%)$ & $<0.0001$ & $18 / 53(33.96 \%)$ & $<0.0001$ & 0.76 & $60 \%{ }^{16}$ \\
\hline hemolysis neonatorum & $0 / 20(0 \%)$ & .. & $0 / 5(0 \%)$ & .. & $0 / 15(0 \%)$ & .. & .. & $0 / 2(0 \%)$ & .. & $0 / 2(0 \%)$ & .. &. &. \\
\hline \multicolumn{14}{|l|}{ Newborns with COVID-19 } \\
\hline \multicolumn{14}{|l|}{ SARS-CoV-2 NAT ${ }^{17}$} \\
\hline positive & $1 / 50(2 \%)$ & .. & $0 / 16(0 \%)$ & .. & $1 / 34(2.9 \% \square$ & .. & 1.0 & $0 / 5(0 \%)$ & .. & $1 / 45(2.2 \%)$ & .. & 1.0 & . \\
\hline negative & $49 / 50(98 \% \square$ & .. & $16 / 16(100 \%)$ & .. & $33 / 34(97.1 \%)$ & .. & 1.0 & $5 / 5(100 \%)$ & .. & $44 / 45(97.8 \%)$ & .. & 1.0 &. \\
\hline \multicolumn{14}{|l|}{ Imaging findings } \\
\hline Pulmonary infections & $17 / 34(50 \%)$ & .. & $5 / 11(45.5 \%)$ &. & $12 / 23(52.2 \%)$ & .. & 1.0 & $2 / 4(50 \%)$ & .. & $15 / 30(50 \%)$ & .. & 1.0 &. \\
\hline Normal & $17 / 34(50 \%)$ & .. & $6 / 11(54.6 \%)$ & .. & $11 / 23(47.8 \%)$ & .. & 1.0 & $2 / 4(50 \%)$ & .. & $15 / 30(50 \%)$ & .. & 1.0 & $*$ \\
\hline \multicolumn{14}{|l|}{ Viral Antibody test ${ }^{18}$} \\
\hline $\mathrm{IgG}+\mathrm{IgM}+$ & $1 / 3(33.3 \%)$ & .. &. &. & $1 / 3(33.3 \%)$ & .. & .. & .. & .. & $1 / 3(33.3 \%)$ & .. &. & $*$ \\
\hline IgG+IIgM- & $2 / 3(66.7 \%)$ &. &. &. & $2 / 3(66.7 \%)$ & .. & .. & .. & .. & $2 / 3(66.7 \% \square$ & .. &. &. \\
\hline IgG-IIgM+ & $0 / 3(0 \%)$ &. & .. & .. & $0 / 3(0 \%)$ & .. & .. & .. & .. & $0 / 3(0 \%)$ & .. &. & . \\
\hline IgG-IIgM- & $0 / 3(0 \%)$ &. &. &. & $0 / 3(0 \%)$ & .. & .. & .. & .. & $0 / 3(0 \%)$ & .. &. &. \\
\hline $\begin{array}{l}\text { Imaging findings with } \\
\text { Pulmonary infections, NAT } \\
\text { negative }\end{array}$ & $16 / 32(50 \%)$ & .. & .. & .. & .. & .. & 1.0 & $2 / 4(50 \%)$ & .. & $14 / 28(50 \%)$ & .. & 1.0 &. \\
\hline $\begin{array}{l}\text { Normal imaging findings, } \\
\text { NAT negative }\end{array}$ & $16 / 32(50 \%)$ & .. & $5 / 9(55.6 \%)$ & .. & $11 / 23(47.8 \%)$ & .. & 1.0 & $2 / 4(50 \%)$ & .. & $14 / 28(50 \%)$ & .. & 1.0 & . \\
\hline
\end{tabular}

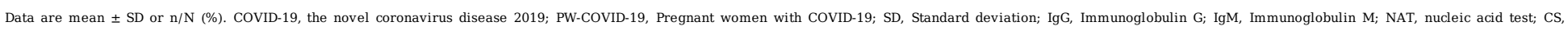
Cesarean section;

1. Of the 78 newborns, there were three twins.

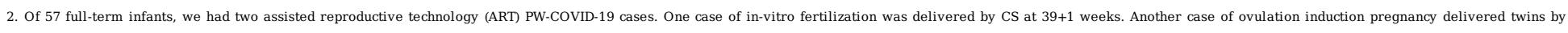
CS at $37+2$ weeks. Their maternal and fetal outoomes had no significant difference with the spontaneous pregnancy PW-COVID-19.

3. P value was calculated between newborns of PW-COVID-19 and the reference ranges of newborns.

4. $\mathrm{P}$ value was calculated between the preterm-infant group in our cases and the reference ranges of newborns.

5. P value was calculated between the term-infant group in our cases and the reference ranges of newborns.

6. P value was calculated between the term-infant group and preterm-infant group in our cases

7. $\mathrm{P}$ value was calculated between vaginal delivery group in our cases and the reference ranges of newborns.

8. P value was calculated between CS group in our cases and the reference ranges of newborns.

9. P value was calculated between CS group and vaginal delivery group in our cases.

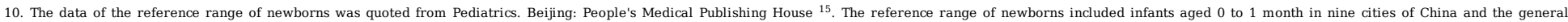
neonatal morbidity.

11. The data of the gender ratio at birth was quoted from Chao $\mathrm{F}$, et al. ${ }^{16}$

12. Data regarding the feeding patterns were missing for 17 neonates.

13. The data of cord entanglement, amniotic fluid pollution, placental abruption, and atrial septal defect was analyzed based on all neonates $(n=78)$.

14. The data was quoted from Benn PA, et al. ${ }^{17}$

15. Sixty-two neonates were confirmed whether have hyperbilirubinemia.

16. The data was quoted from Basu S, et al. ${ }^{18}$

17. NAT results of 50 newborns were known.

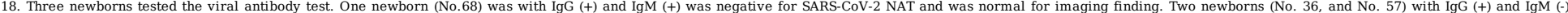
were both negative for SARS-CoV-2 NATs but found pulmonary infections in imaging findings

\section{Referenc:}

1. Guan WJ, Ni ZY, Hu Y, et al. Clinical Characteristics of Coronavirus Disease 2019 in China. The New England journal of medicine 2020.

2. Wong SF, Chow KM, Leung TN, et al. Pregnancy and perinatal outcomes of women with severe acute respiratory syndrome. American journal of obstetrics and gynecology 2004; 191(1): 292-7.

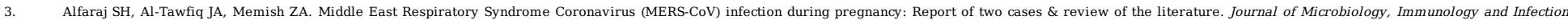
2019; 52(3): 501-3.

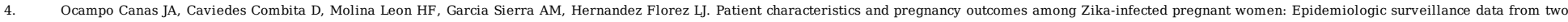
cities in Colombia, 2015-2016. International journal of gynaecology and obstetrics: the official organ of the International Federation of Gynaecology and Obstetrics 2020; 148 Suppl 2(S2): 4-8.

5. Siston AM, Rasmussen SA, Honein MA, et al. Pandemic 2009 influenza A(H1N1) virus illness among pregnant women in the United States. JAMA 2010; 303(15): 1517-25. 


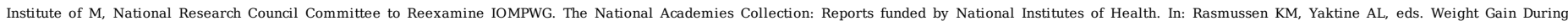
Pregnancy: Reexamining the Guidelines. Washington (DC): National Academies Press (US)

Copyright @ 2009, National Academy of Sciences.; 2009 .

Xing Xie, Beihua kong, Duan. T. Obstetrics and Gynecology, the Ninth edition.: Beijing: People's Medical Publishing House; 2018.

Yang W, Lu J, Weng J, et al. Prevalence of diabetes among men and women in China. The New England journal of medicine 2010; 362(12): 1090-101.

Azulay CE, Pariente G, Shoham-Vardi I, Kessous R, Sergienko R, Sheiner E. Maternal anemia during pregnancy and subsequent risk for cardiovascular disease. J Matern Fetal Neonatal Med 2015; 28(15): 1762-5.

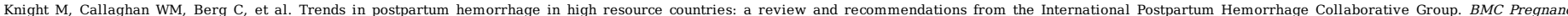
Childbirth 2009. 9. 55.

12. Jones RK, Jerman J. Abortion Incidence and Service Availability In the United States, 2014. Perspect Sex Reprod Health 2017; 49(1): 17-27.

13. Chawanpaiboon S, Vogel JP, Moller AB, et al. Global, regional, and national estimates of levels of preterm birth in 2014: a systematic review and modelling analysis. Lancet Glob Health 2019; 7(1): e37-e46.

14. Chen D, Cui S, Liu C, Oi H, Zhong N. Stillbirth in China. Lancet (London, England) 2016; 387(10032): 1995-6.

15. Wang. WP, Sun. K, Chang. LW, et al. Pediatrics, the Ninth edition. Beijing: People's Medical Publishing House. ; 2008.

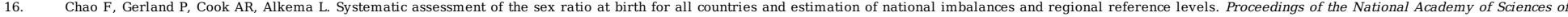
the United States of America 2019: 116(19): 9303-11.

17. Benn PA, Schonhaut AG, Hsu LY. A high incidenœe of maternal œell contamination of amniotic fluid cell cultures. Am J Med Genet 1983; 14(2): 361-5.

18. Basu S, De D, Shukla RC, Kumar A. Difference in cerebral blood flow velocity in neonates with and without hyperbilirubinemia. J Epidemiol Glob Health 2014; 4(2): 97-106.

\section{Appendix}

The authors' full names and academic degrees are as follows: ShuJie Liao , M.D. , Renjie Wang , M.M. , Di Wu, M.M. , Dong Fang, M.D. , Dirong Dong, M.D. , Zhengui Tao, M.D. , Hui Yang, M.D. , Wanjang Zeng, M.D. , Qionglin Peng, M.D. , Jing Peng, M.D. , Yuping Wu, M.D. , Suhua Chen, M.D. , Xingguang Lin, M.D. , Guoping Xiong, M.D. , Xiulan Ma, M.D. , Aiping You, M.D. , Liping Lu, M.D. Wan-qiang Dai , M.S , Cheng Hu , M.S. , Jun Zheng, M.D. , Fengyi Xiao, M.D. , Yangchun Wang, M.D. , Wencong He, M.D. , Hua Li, M.D. , Hui Xing, M.D. , Yanli Huang, M.D. , Derong Sun, M.D. , Ping Cheng, M.D. , Hongmei Jin, M.D. , Zhuchun Zhang, M.D. , Dongfang Su, M.D. , Rong Huang, M.D. , Chunlian Zhang, M.D. , Xueqin Liu, M.D. , Zhian Zhang, M.D. , Ying Bi, M.D. , Ling Wang, M.D. , Xiaoling Hu, M.D. , Qibo Shen, M.D. , Liucheng Zhao, M.D. , Cuimin Fu, M.D. , Shulan Dai, M.D. , Rong Du, M.D. , Ling Wang, M.D. , Jianli Wu, M.D. , Shaoshuai Wang, M.D. , Dan Lv , M.M. , Rui Long , M.M. , Jing Peng , M.M. , Chao Qian , M.D. , Wei Pan , Ph.D. , Yun Zhao, M.D. , Ling Feng, M.D. , Dongrui Deng, M.D. , Wei Zhang, M.D.

The authors' affiliations are as follows: Department of Obstetrics and Gynecology, Tongji Hospital, Tongji Medical College, Huazhong University of Science and Technology(Shujie Liao, R. W., D. W., W. Z., S. C., X. L., J. W., S. W., D. L. , R. L.,L. F., D. D.), Egang Hospital of Ezhou City(Z. T., Q. P.), Department of Obstetrics, Maternal and Child Health Hospital of Hubei Province, Tongji Medical College, Huazhong University of Science and Technology(H. Y., J. P., Y. Z.), Zhongnan Hospital of Wuhan University(D. D., W. Z.), Andrology Center, Peking University First Hospital; Department of Urology, Peking University First Hospital; Institute of Urology, Peking University(D. F.), Wuhan Jiangxia District People's Hospital(J. P., Y. W.), The Central Hospital of Wuhan(G. X., X. M.), Maternal and Child Hospital of Huangshi City(A. Y.), The first people's Hospital of Xiaochang County(L. L.), School of Economic and Management, Wuhan University(W. D., C. H.,Wei Pan), The First People's Hospital of Xianning(J. Z.), Suizhou Central Hospital(F. X.), The people's hospital of Xishui(Y. W.), Yichang Central People's Hospital, The First College of Clinical Medical Science, China Three Gorges University(W. H., H. L.), Xiangyang Central Hospital Affiliated to Hubei University of Arts and Science(H. X., Y. H.), Jing Men NO.2 People's Hospital(D. S.), The People's Hospital of Fangxian(P. C.), People's Hospital of Macheng City(H. J.), Wuhan Xinzhou District People's Hospital(Z. Z., D. S., R. H.), Taihe Hospital Affiliated to Hubei University of Medicine(C. Z., X. L.), Huanggang Central Hospital, Dabieshan Regional Medical Center(Z. Z.), Wuhan Red Cross Hospital(Y. B.), People's Hospital of Huangmei County(L. W.), The People's Hospital of Hanchuan(X. H.), The First People's Hospital of Zaoyang(Q. S.), The People's Hospital of Hongan(L. Z.), The People's Hospital of Dawu(C. F.), Wuhan Dongxihu District People's Hospital(S. D., R. D.), Yangxin maternal and Child Health Hospital(C. Q.), The People's Hospital of Jiangling(L. W.), School of Applied Economics, Renmin University of China(Wei Pan)--all in China.

\section{Figures}




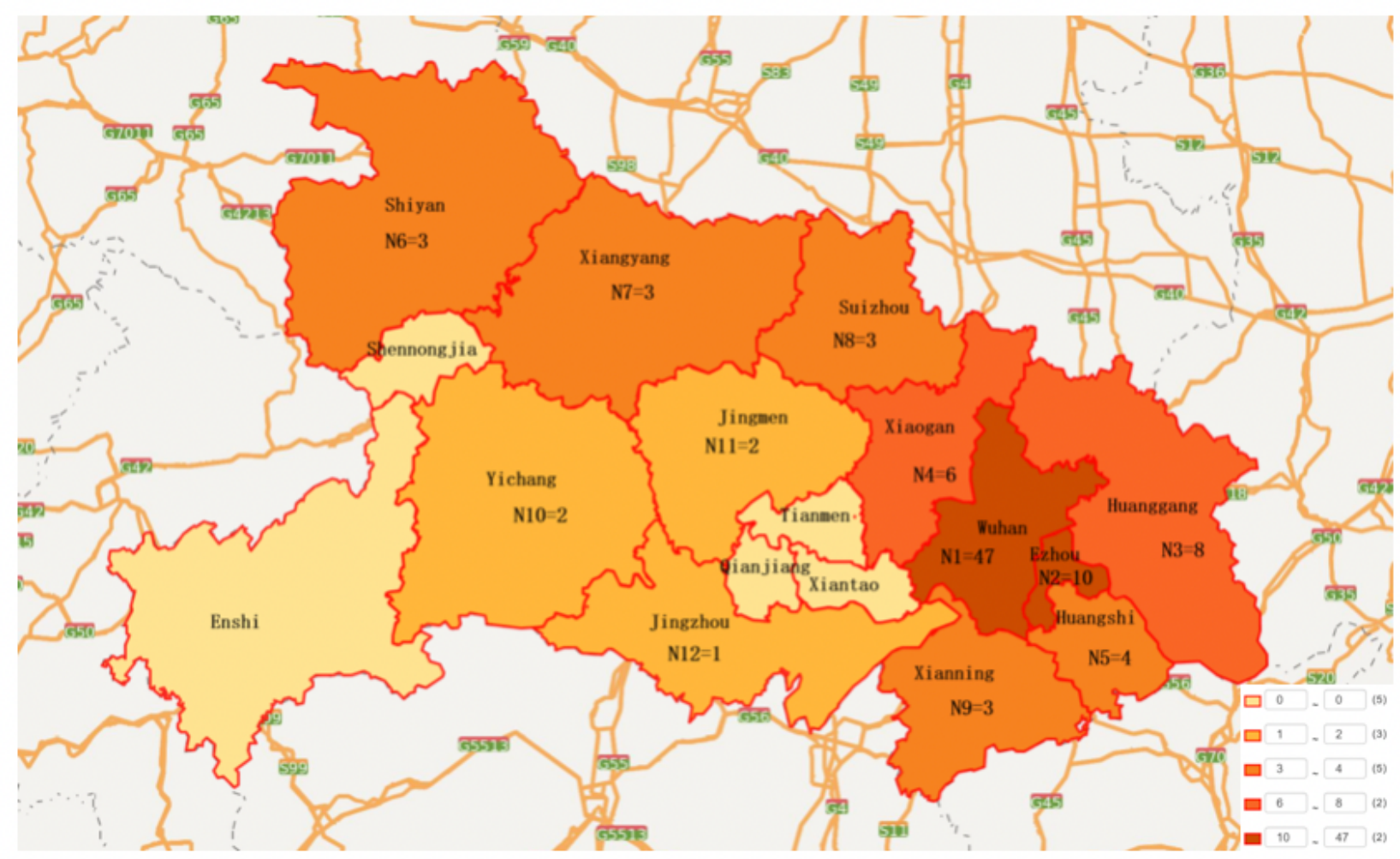

\section{Figure 1}

Distribution of 92 PW-COVID-19 from 27 hospitals in 12 regions of Hubei province China. Note: The designations employed and the presentation of the material on this map do not imply the expression of any opinion whatsoever on the part of Research Square concerning the legal status of any country, territory, city or area or of its authorities, or concerning the delimitation of its frontiers or boundaries. This map has been provided by the authors.

\section{Supplementary Files}

This is a list of supplementary files associated with this preprint. Click to download.

- Supplementary.docx 